\title{
Treatment of Metal-Laden Hazardous Wastes with Advanced Clean Coal Technology By-Products
}

\author{
Quarterly Report \\ September 30 - December 30, 1996
}

\author{
By: \\ James T. Cobb, Jr.; Ronald D. Neufeld \\ Jean R. Blachere; B. Vourneen Clifford \\ Jesse Pritts; Carl F. Bender
}

Work Performed Under Contract No.: DE-FC21-94MC31175

For

U.S. Department of Energy

Office of Fossil Energy

Federal Energy Technology Center

P.O. Box 880

Morgantown, West Virginia 26507-0880

RECEIVED

OCT 131998

OSTI

By

University of Pittsburgh

320 William Pitt Way

Pittsburgh, Pennsylvania 15238

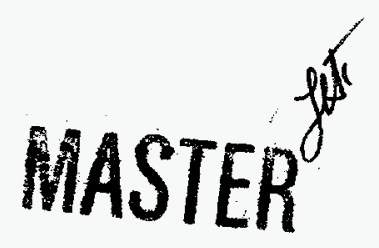




\section{Disclaimer}

This report was prepared as an account of work sponsored by an agency of the United States Government. Neither the United States Government nor any agency thereof, nor any of their employees, makes any warranty, express or implied, or assumes any legal liability or responsibility for the accuracy, completeness, or usefulness of any information, apparatus, product, or process disclosed, or represents that its use would not infringe privately owned rights. Reference herein to any specific commercial product, process, or service by trade name, trademark, manufacturer, or otherwise does not necessarily constitute or imply its endorsement, recommendation, or favoring by the United States Government or any agency thereof. The views and opinions of authors expressed herein do not necessarily state or reflect those of the United States Government or any agency thereof. 


\section{DISCLAIMER}

Portions of this document may be illegible electronic image products. Images are produced from the best available original document. 


\section{TABLE OF CONTENTS}

$\begin{array}{ll}\text { Executive Summary } & 1\end{array}$

$\begin{array}{lc}\text { Introduction } & 3\end{array}$

$\begin{array}{ll}\text { Laboratory and Field Work } & 4\end{array}$

$\begin{array}{lr}\text { Reports and Presentations } & 9\end{array}$

$\begin{array}{lr}\text { Outside Contacts } & 10\end{array}$

$\begin{array}{ll}\text { Administrative Aspects } & 11\end{array}$

$\begin{array}{ll}\text { Plans for the Next Quarter } & 13\end{array}$

Appendix A - Chemistry and Microstructure of Sandblast Waste and Its Residue $\quad 14$ When Treated with By-Products from Clean Coal Technologies 


\section{EXECUTIVE SUMMARY}

During the fifth quarter of Phase 2, work continued on conducting scholarly work, preparing for field work, preparing and delivering presentations, and making additional outside contacts.

\section{Laboratory Analyses}

Examination of wastes and treatment products were suspended during this quarter to allow scholarly work to be completed. Examination of treatment products will resume in the next quarter.

\section{Scholarly Work}

The two graduate students assigned to this project have both continued their work toward preparing their theses during the quarter. One student has completed his thesis. The other completed evaluations of the solidified sandblast residue using $x$-ray diffraction and the scanning electron microscope and has nearly completed her thesis.

\section{Preparation for Field Work}

The search for a new subcontractor, precipitated by the withdrawal of Mill Service, Inc. (MSI), continued. EQ Company, Ypsilanti, Michigan, was visited. The project team has decided not to continue discussions with them. As the quarter ended, only one other candidate, Heritage Environmental Services, Inc., was still considering an invitation.

\section{Reports and Presentations}

A poster entitled "Stabilization/Solidification of Metal-Laden Hazardous Wastes with Advanced Clean-Coal Technology By-Products" was presented at the Third University of Pittsburgh Environmental and Energy Colloquium and Poster Fair in Benedum Hall on October 23, 1996.

\section{Qutside Contacts}

The principal investigator provided the E50.03 subcommittee of the American Society for Testing and Materials with review comments on a proposed "Standard Practice for Use of Coal Combustion By-Products for Stabilization of Waste Containing Arsenic, Boron, Chromium, Molybdenum, Selenium, Vanadium and Other Oxyanionic Species." 
The coprincipal investigator was notified of the rejection of his related proposal on "Stabilization of DOE Hazardous [Mixed] Wastes with Clean-Coal Technology By-Products" in response to Program Notice 96-10, submitted to U.S.DOE, Germantown, Maryland.

\section{Plans for the Next Quarter}

During the quarter from December 30, 1996 through March 30, 1997, work will continue on Tasks 4 and 5 of Phase 1.

Work on Task 1 of Phase 2 will continue. When the new subcontractor is identified and aboard, the test plan for Phase 2 will be prepared. It will include the detailed plan for the field work and related laboratory activities.

The continuing graduate student and a new one, assigned to this project, will continue scholarly work during this quarter. 


\section{INTRODUCTION}

This ninth quarterly report describes work done during the ninth three-month period of the University of Pittsburgh's project on the "Treatment of Metal-Laden Hazardous Wastes with Advanced Clean Coal Technology By-Products."

This report describes the activities of the project team during the reporting period. The principal work has focussed upon microscopic evaluation of sandblast residue treated with two by-products, completing scholarly work, seeking a subcontractor to replace Mill Service, Inc. (MSI) for the field work of Phase 2, preparing and giving a poster, and making and responding to several outside contacts. 


\section{LABORATORY AND FIELD WORK}

\section{Laboratory Analyses}

Phase 1 laboratory work at the University of Pittsburgh was concluded during this. The work consisted of examining the microstructure of the sandblast residue from paint removal in a building and of the products of treating it with clean coal technology by-products. This work essentially comprised the scholarly activities of one of the two graduate students, working on the project.

\section{Solidification Testing of Treatment Residue}

Laboratory work on this topic have been suspended until the site of the demonstration of Phase 2 is identified and a test plan approved.

\section{Metals Analysis of Treatment Residue}

Laboratory work on this topic was suspended during this quarter while the focus was placed exclusively upon scholarly work. It will be resumed during the next quarter.

\section{Scholarly Activity}

The two graduate students continued work towards their respective Master's theses during the quarter. Mr. Pritts completed his M.S. thesis, entitled "Stabilization and Solidification of Metal-Laden Hazardous Wastes with Clean-Coal-Technology By-Products." Professor Neufeld served as the major advisor for this presentation.

During the last quarter Ms. Clifford began microscopic evaluations of the treated sandblast waste mixtures after these same curing times, in addition to the raw materials used, by both $x$-ray diffraction and scanning electron microscopy. That work was completed during this quarter and her M.S. thesis, entitled "The Stabilization of a Hazardous Sandblast Waste with Advanced Clean Coal Technology By-Products." What follows are the sections of her thesis which describe the microscopic evaluations.

\section{Chemistry and Microstructure}

Evaluation of chemistry and microstructure was performed on the treated waste mixtures prepared for solidification testing after curing times of $1,3,7,14$, and 28 days, as well as on the raw materials. Morphology and elemental composition were evaluated through the use of scanning electron microscopy (SEM), whereas mineralogy was determined through the use of $x$-ray diffraction (XRD). A detailed description of these two different techniques is provided below. 
Scanning Electron Microscopy. SEM was used to create a magnified image of the sample surface. In this process, a high energy focused beam of electrons, several tens of angstroms in diameter, was used to scan palladium coated samples. Interaction of the beam with the outermost electron shells of the atoms on the surface produced secondary electrons which were collected by a detector and displayed on a cathode ray tube screen, resulting in an image of the surface. Two different scanning electron microscopes, a JEOL 35CF and a Philips XL30 with a field emission source, were used during the course of this investigation. In preparation, all samples were dried in a $60^{\circ} \mathrm{C}$ oven, under vacuum, for two hours prior to examination under the SEM. All dried samples were transported and stored in a desiccator. For examination under the JEOL 35CF SEM, all specimens were mounted to sample stubs using conductive carbon tape. As the Philips XL30 SEM was used to detect light elements such as carbon, conductive silver paint was used instead of carbon tape to secure the specimen to the sample stub in order to avoid any interference from the mounting media. All samples were coated with palladium using a Polaron Equipment Limited SEM Coating Unit E5000. Each sample was coated three times for two minutes at $1.0 \mathrm{kV}$, in order to prevent the sample from charging while in the microscope. While using both microscopes, the secondary electron mode was used to characterize morphology, while the backscatter electron mode was used to locate the lead metal within the specimen. The JOEL 35CF microscope was used in conjunction with a $4 \pi$ computer system with a DTSA program for elemental analysis. The Philips XL30 microscope was used in conjunction with an EDAX, both eDXi and eDXAUTOp, analytical system with a super-ultra thin window $\mathrm{Si}-\mathrm{Li}$ detector for elemental analysis. Use of the aforementioned techniques made it possible to analyze small volumes of samples, approximately as small as $1(\mu \mathrm{m})^{3}$.

X-Ray Diffraction. XRD was used to identify the crystalline phases present in the samples. In preparation, samples were ground into a fine powder using a mortar and pestle. Approximately 2 grams of each powdered sample was then mounted on a glass cover slide in a square sample holder. Each finely ground sample was rotated while being irradiated with a monochromatic beam of x-rays. Mineralogy was determined by XRD using the powder method in an X'Pert diffractometer system (Philips, Almelo, Holland) using $\mathrm{Cu} \mathrm{K}_{\alpha}$ radiation. The system was operated using a tube voltage of $40 \mathrm{kV}$ and a tube current of $30 \mathrm{~mA}$. The different crystalline phases diffracted the beam of $x$-rays at different angles of rotation $(\theta)$ and produced strong signals which were recorded digitally as counts per seconds versus the $2 \theta$ angle. A $0.5^{\circ}$ beam slit and a $0.3^{\circ}$ detector slit were used in scanning $2 \theta$ from $3^{\circ}$ to $80^{\circ}$ at a rate of $2.4^{\circ} / \mathrm{min}$. The peak intensities were directly related to the degree of sample crystallinity and the detection limit for well crystallized phases was of the order of 1-3\%. The angles at which peaks occurred were then used with Bragg's law to calculate the spacing between the atomic planes of the different crystalline phases. Diffraction patterns were generated using PC-APD (PW1877) Analytical Powder Diffraction software version 3.6. Peaks in the resulting diffraction patterns were identified using PC-Identify software (PW1876) version 1.0 and comparison to a data base of known atomic plane spacings, the Joint Committee on Powder Diffraction Standards (JCPDS) files, in order to determine the nature of the crystalline phases for mineral identification. The presence of the 3 peaks of strongest intensity of a given phase, as given by the reference pattern for that particular phase, was required for positive phase identification. 
Results and Discussion

The appendix contains a copy of those sections of Ms. Clifford's thesis devoted to the presentation of the results and discussion of the chemistry and microstructure studies.

\section{Conclusions and Recommendations}

The speciation of the hazardous constituent within the raw waste was found to be a basic lead carbonate, as determined by XRD analysis. Phase characterization by XRD also indicated that the metal speciation of the raw waste remained unchanged in the resulting treated waste mixtures. Microstructure characterization by SEM revealed that the particles of basic lead carbonate scattered throughout the treated waste mixtures were surrounded by or encapsulated in a matrix of very fine material consisting of calcium, sulfur, and silicon. The results of the XRD analysis, when interpreted in conjunction with the results of the SEM analysis, imply that physical encapsulation on a microscopic scale is the principal mechanism responsible for stabilization.

The results of this study indicate several areas worthy of further investigation. The long-term effectiveness of stabilization and solidification should be evaluated. For this purpose, it is recommended that these same evaluations be conducted after curing times of at least 90 days to gain a better understanding of the long term effects. Long-term evaluations may be particularly promising for the CFBC residue as the immediate leachable lead concentration of the waste treated with this by-product significantly decreased after mellowing for 24 hours. It is also recommended that the chemistry and microstructure of this treated waste mixture be evaluated by SEM and XRD analysis. Long-term evaluations may also be of particular interest for the sandblast waste treated with $50 \%$ PFBC residue as the first appearance of crystal growth in this treated waste mixture did not occur until 28 days. At this time, it was too early to determine the exact composition of the crystal formation. Long-term evaluations would give further insight into the chemistry and microstructure of the matured crystals, thus determining their composition and related effect upon stabilization and solidification.

It was hypothesized that the PFBC residue did not enter into pozzolanic hydration reactions as readily as it has the potential to due to the fact that it may have become hydrated during storage and subsequent utilization over the last year. Further studies are necessary between fresh and hydrated by-products to determine the resulting effect on stabilization ability. In addition, further experiments could be performed using additional binders and reagents to the $F B C$ residues in order to improve stabilization ability. The use of additives, such as trisodium phosphate (TSP), which is currently used by the local TSD facility as a treatment chemical, to the sandblast waste treated with the PFBC residue may help bring the leachable concentration of lead to below the current BDAT standard of $5 \mathrm{mg} / \mathrm{L}$.

The total porosity and pore size distribution of a solid affects its physiomechanical properties and permeability characteristics. The correlation between porosity and permeability is dependent upon total porosity, pore size distribution, and the morphology and configuration of the pores. The determination of total porosity and pore size distribution may be used as potential indicators of the physiomechanical properties and leaching potential of stabilized/solidified wastes. 
Finally, the degree of encapsulation is enhanced by the type and energy per unit mass of mixing. Bench-scale laboratory samples are generally well blended with a high energy per unit mass as compared to full-scale batches mixed in the field. This gives rise to a greater degree of encapsulation in the laboratory as a larger number of particles become entrapped. Field studies should be conducted mixing 50 ton commercial-scale batches to ensure the same degree of stabilization as was demonstrated in the laboratory.

\section{Preparation for Field Work}

On July 25, 1996 a letter had been sent to EQ Company in Ypsilanti, Michigan, telling them about the project and asking for their interest in joining it. In response, Professor Cobb paid a visit to EQ Company on November 12, 1996, meeting with David M. Lusk, Vice President for Hazardous Waste Operations, and Michael Favor, General Manager. Here are the points that were covered in the discussion.

1. EQ has a basic interest in our project. They look for inexpensive treatment chemicals. If certain conditions can be met, they will participate, even though these chemicals may be useful for only a small fraction of their wastes. If it turns out that the chemicals cannot be used with their wastes for any reason, the outcome of the project would be more to the advantage of their competitors to the east, where there are more obvious sources of byproduct. So, EO, as a business, would have a success in the project only if EO uses the process on a competitive playing field that is at least level.

2. The principal condition, therefore, is that there will be sufficient usable by-product within 50 miles of EQ in Ypsilanti, Michigan, to serve as a commercial source. A second condition is that the by-products instantly bring the concentrations to UTS levels (for example $0.37 \mathrm{ppm}$ for lead, NOT $5 \mathrm{ppm}$ ). This is a relatively difficult task for our materials.

3. EQ treats batches an order of magnitude larger than MSI. Typically, 220 yards of treated waste are produced per batch. However, at off-peak hours, batches of about 100 yards probably can be used.

4. EQ would line up the wastes to be treated.

5. EQ feels that the data in our topical report is very robust, much more so than similar studies they have seen.

6. EQ has filed for using their hazardous (RCRA) fill as a toxic (TOSCA) fill. For the past six months the site has been a lightning rod for public assessment of this request. Even so, we would hope that, because the site is fully permitted as a RCRA fill, an EA would not be required by U.S.DOE.

7. EQ wants us to find the by-products in their area. They provided names of contacts at GM Worldwide Powerhouse Operation, Wayne County Air Quality Management, and the Air Quality Division of the Michigan Department of Environmental Quality. They also suggested getting in touch with Detroit Edison. 
8. EO feels that we should have an easier time lining up a treater farther east, where byproduct is more available. If U.S.DOE is less likely to require an EA, they suggest going back to others we spoke with earlier.

As a result of this visit, the project team has decided not to continue discussions with EO Company. 


\section{REPORTS AND PRESENTATIONS}

On October 23, 1996 the project team presented a poster on "Stabilization/Solidification of Metal-Laden Hazardous Wastes with Advanced Clean Coal Technology By-Products" at the Third University of Pittsburgh Environment and Energy Colloquium and Poster Fair on the eleventh floor of Benedum Hall. Here is the abstract of the poster, which was included in the abstract booklet for the event.

The development of clean coal technologies to reduce atmospheric $\mathrm{SO}_{\mathrm{x}}$ and $\mathrm{NO}_{\mathrm{x}}$ emissions from coal-fired power plants has created a variety of lime-containing by-products with pozzolanic and cementitious characteristics that may prove beneficial to the hazardous waste treatment industry. The objective of this research was to evaluate the ability of a spray-dry scrubber residue and two FBC residues to successfully stabilize/solidify seven different metal-laden hazardous wastes. Stabilization was measured by TCLP metals analysis of 15 heavy metals, lead being the metal of greatest concern. For those treatments that demonstrated successful stabilization, solidification was measured by compressive strength testing. In addition, microscopic evaluations of the raw materials and treated waste mixtures were performed by $x$-ray diffraction and scanning electron microscopy. Results demonstrate that certain hazardous wastes are highly amenable to chemical stabilization, and that while certain byproducts provide superior stabilization, others provide superior solidification. 


\section{OUTSIDE CONTACTS}

\section{American Society for Testing and Materials}

As a result of attending the meeting in July of the E50.03 subcommittee of the American Society for Testing and Materials (ASTM), the principal investigator received a draft from Debra Pflughoeft-Hassett of the proposed "Standard Practice for Use of Coal Combustion By-Products for Stabilization of Wastes Containing Arsenic, Boron, Chromium, Molybdenum, Selenium, Vanadium and Other Oxyanionic Species." Professor Cobb provided Ms. PflughoeftHassett with a set of comments he generated with assistance from Ms. Clifford.

\section{Miscellaneous Topics in Coal Combustion By-Product Utilization}

Prof. Neufeld received notification from the U.S.DOE, Germantown, Maryland, that his proposal entitled "Stabilization of DOE Hazardous [Mixed] Wastes with Clean-Coal Technology By-Products," reported on pages 13-14 of the seventh quarterly technical progress report on this project (dated August 12, 1996), was declined. 


\section{ADMINISTRATIVE ASPECTS}

This section provides monthly highlights and a comparison of progress with the milestone chart.

\section{Special Actions}

No special actions were taken during this quarter.

\section{Monthly Highlights} project.

Here are the highlights of the fifth three month period of the second phase of the

September 30 - October 30.1996

- Chemical and microscopic analyses of sandblast waste and stabilized residues of treated samples of this waste are completed.

- Poster entitled on "Stabilization/Solidification of Metal-Laden Hazardous Wastes with Advanced Clean Coal Technology By-Products" is presented at the Third University of Pittsburgh Environment and Energy Colloquium and Poster.

October 30 - November 30,1996

- EQ Company is visited and the decision is made to discontinue discussions with this company.

- Principal investigator provides a response to the ASTM E50.03 subcommittee on the proposed "Standard Practice for Use of Coal Combustion By-Products for Stabilization of Wastes Containing Arsenic, Boron, Chromium, Molybdenum, Selenium, Vanadiurn and Other Oxyanionic Species."

November 30 - December 30,1996

- Mr. Pritts successfully defends his M.S. thesis, entitled "Stabilization and Solidification of Metal-Laden Hazardous Wastes with Clean-Coal-Technology ByProducts."

\section{Comparison of Progress with Milestone Chart}


The following task for Phase 2 had been scheduled for completion during the first quarter of Phase 2:

- Task 1 - Test Plan for Phase 2

Task 1 still was not completed during the fifth period of this phase. The decision in early April 1996 by METC that an environmental assessment of the Phase 2 project at the Yukon plant of Mill Service, Inc., would have to be conducted and the subsequent withdrawal in late April 1996 by MSI from Phase 2 has necessitated a search for a new subcontractor to host and participate in the commercial test of Phase 2. The test plan for Phase 2 cannot be specified in sufficient detail for presentation until the new subcontractor is identified and can participate in its preparation.

Work continued on two tasks from Phase 1:

- Task 4 - Treatment of Metal-Laden Waste with CCT Solid By-Product

- Task 5 - Data Analysis

Work on Tasks 4 and 5 of Phase 1 will continue into the sixth quarter of Phase 2 . The fourth by-product and the final three residues are no longer being actively sought. When the Phase 2 testing program is initiated, consideration will be given to reestablishing this activity. 


\section{PLAN FOR THE NEXT QUARTER}

During the quarter from December 30, 1996 through March 30, 1997, work will continue on Tasks 4 and 5 of Phase 1.

Work on Task 1 of Phase 2 will continue. When the new subcontractor is identified and aboard, the test plan for Phase 2 will be prepared. It will include the detailed plan for the field work and related laboratory activities.

The continueing graduate student and a new one, assigned to this project, will continue scholarly work during this quarter. 


\section{APPENDIX A}

CHEMISTRY AND MICROSTRUCTURE OF SANDBLAST WASTE AND ITS RESIDUE WHEN TREATED WITH BY-PRODUCTS FROM CLEAN COAL TECHNOLOGIES 
4.1.3 Chemistry and Microstructure

Characterization of the three CCT by-products was performed using scanning electron microscopy (SEM) and x-ray diffraction (XRD) in order to provide valuable insight into the chemistry and microstructure of these materials. Elemental chemical analysis of the by-products was performed by SEM. Of equal importance to the bulk chemistry of the byproducts is the mineralogy. Mineralogical characterization was performed by XRD to determine the crystalline phases present in the by-products. The results of both the elemental and mineralogical analyses of each of the three by-products are summarized in Table 18.

Elemental analysis of the by-products by SEM revealed that they each consist of nine major elements: calcium, sulfur, silicon, aluminum, iron, magnesium, carbon, and oxygen. These elements are consistent with the elemental compositions of fly ash, sulfur sorbents, and sulfur sorbent reaction products, which together comprise the by-products. From the literature review, it was found that fly ash is comprised mostly of $\mathrm{SiO}_{2}, \mathrm{Al}_{2} \mathrm{O}_{3}$, and $\mathrm{Fe}_{2} \mathrm{O}_{3}$, with smaller amounts of $\mathrm{MgO}$ and $\mathrm{CaO}$. In addition to fly ash, these by-products also contain excess sorbent (either lime or dolomite) and reaction products (such as calcium sulfite and calcium sulfate), thereby contributing to the elemental compositions of the calcium, magnesium, and sulfur found. Potassium and titanium were also found in a couple of the by-product samples analyzed, but not in the abundance of the other elements. The potassium is most likely from the coal ash composition of the by-products, as Table 1 in the literature review revealed that trace amounts of $\mathrm{K}_{2} \mathrm{O}$ were found in some fly ashes. 
Table 18

Elemental and Mineralogical Analyses of the CCT By-Products

\begin{tabular}{|c|c|c|}
\hline CCT By-Product & Elemental Analysis & Mineralogical Analysis \\
\hline $\begin{array}{c}\text { Spray Dry } \\
\text { Scrubber Residue }\end{array}$ & $\begin{array}{c}\mathrm{Ca}, \mathrm{S}, \mathrm{Si}, \mathrm{Al}, \mathrm{Fe}, \mathrm{Mg}, \mathrm{C}, \mathrm{O} \\
\mathrm{K} \text { (minor) } \\
\mathrm{Ti} \text { (minor) }\end{array}$ & $\begin{array}{l}\text { Calcium Sulfite Hemihydrate } \\
\qquad\left(\mathrm{CaSO}_{3} \cdot 1 / 2 \mathrm{H}_{2} \mathrm{O}\right) \\
\text { Mullite }\left(\mathrm{Al}_{6} \mathrm{Si}_{2} \mathrm{O}_{13}\right) \\
\text { Quartz }\left(\mathrm{SiO}_{2}\right) \\
\text { Hematite }\left(\mathrm{Fe}_{2} \mathrm{O}_{3}\right) \\
\text { Corundum }\left(\mathrm{Al}_{2} \mathrm{O}_{3}\right)\end{array}$ \\
\hline PFBC Residue & $\begin{array}{c}\mathrm{Ca}, \mathrm{S}, \mathrm{Si}, \mathrm{Al}, \mathrm{Fe}, \mathrm{Mg}, \mathrm{C}, \mathrm{O} \\
\mathrm{K} \text { (minor) }\end{array}$ & $\begin{array}{l}\text { Anhydrite }\left(\mathrm{CaSO}_{4}\right) \\
\text { Dolomite }\left[\mathrm{CaMg}\left(\mathrm{CO}_{3}\right)_{2}\right] \\
\text { Periclase }(\mathrm{MgO}) \\
\text { Hematite }\left(\mathrm{Fe}_{2} \mathrm{O}_{3}\right) \\
\text { Quartz }\left(\mathrm{SiO}_{2}\right)\end{array}$ \\
\hline CFBC Residue & $\mathrm{Ca}, \mathrm{S}, \mathrm{Si}, \mathrm{Al}, \mathrm{Fe}, \mathrm{Mg}, \mathrm{C}, \mathrm{O}$ & $\begin{array}{l}\text { Anhydrite }\left(\mathrm{CaSO}_{4}\right) \\
\text { Quartz }\left(\mathrm{SiO}_{2}\right) \\
\text { Hematite }\left(\mathrm{Fe}_{2} \mathrm{O}_{3}\right) \\
\text { Corundum }\left(\mathrm{Al}_{2} \mathrm{O}_{3}\right)\end{array}$ \\
\hline
\end{tabular}

A representative SEM spectrum of the spray dry scrubber residue is presented in Figure 5. This spectrum shows the dominant presence of calcium and sulfur, which form the reaction product calcium sulfite hemihydrate. Aluminum and silicon are also present in significant quantities, corresponding to the presence of mullite. Figure 6 shows a representative spectrum of the $\mathrm{PFBC}$ residue. Again, calcium and sulfur are the dominant elements present. Table 18 shows that these two elements combine to form anhydrite. 


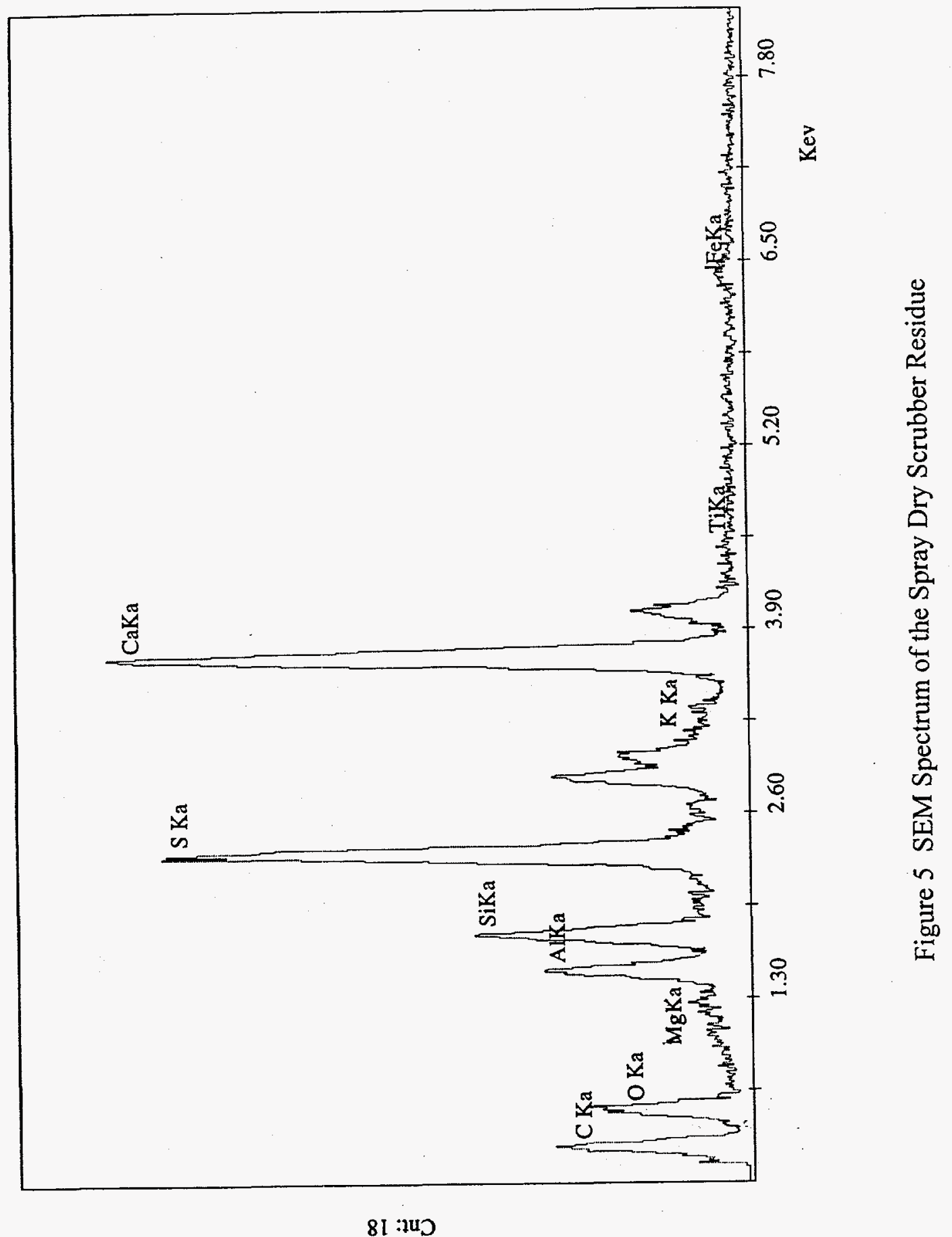


In addition, there is a significant amount of magnesium present as a result of the use of dolomite, instead of lime or limestone, as the sorbent in the CCT process. Overall, the elemental analyses presented in Table 18, and the corresponding SEM spectrums shown in Figures 5 and 6 , are consistent with the results of the by-product characterization previously given in Table 15. It should be noted that the unlabeled peak in between the sulfur and calcium peaks in the SEM spectrums presented in Figures 5 and 6 is palladium. Palladium was used to coat the samples prior to examination under the microscope in order to prevent them from charging. This peak was not labeled in order to avoid the implication that palladium was present in the treated waste samples.

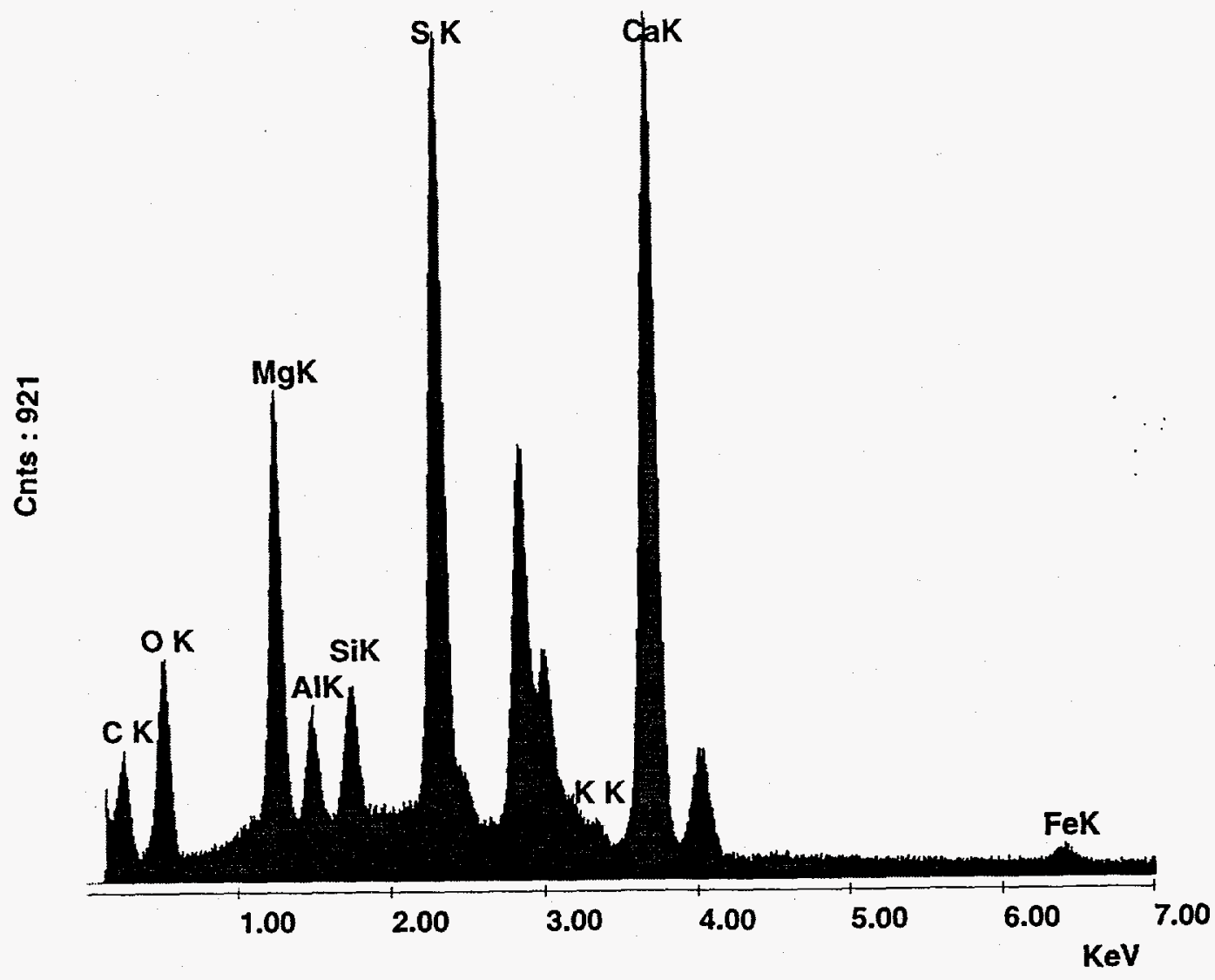

Figure 6 SEM Spectrum of the PFBC Residue 
Although minor amounts of potassium and titanium were identified in a couple of the by-product samples, no corresponding mineral phases were positively identified. This would imply that potassium and titanium constitute less than $1 \%$ of the by-product, which is below the detection limits of XRD. Those crystalline phases that could be identified unambiguously from the diffraction pattems by identifying the 3 peaks of strongest intensity for each phase, as given by reference patterns, are presented in Table 18 .

For each of the by-products, the sulfur sorption reaction product was positively identified. The spray dry scrubber residue was found to consist primarily of calcium sulfite hemihydrate $\left(\mathrm{CaSO}_{3} \cdot \frac{1}{2} \mathrm{H}_{2} \mathrm{O}\right)$, whereas the two $\mathrm{FBC}$ residues consist of anhydrite $\left(\mathrm{CaSO}_{4}\right)$. This difference is mainly due to the lower flue gas reaction temperatures of the spray dry scrubber process. When anhydrite is heated above $300-400^{\circ} \mathrm{F}$, as is the case for the two FBC residues, it is converted to an insoluble form as the $\mathrm{CaSO}_{4}$ does not readily hydrate upon contact with water vapor. This process, in which the anhydrite in the two FBC residues does not readily hydrate to hemihydrate $\left(\mathrm{CaSO}_{4} \cdot 1 / 2 \mathrm{H}_{2} \mathrm{O}\right)$ or further to gypsum $\left(\mathrm{CaSO}_{4} \cdot 2 \mathrm{H}_{2} \mathrm{O}\right)$ as a result of exposure to the high temperatures in a boiler, is referred to as "dead burning" and yields a less reactive end-product. These differences in the composition of the reaction products were expected from the literature review and are consistent with the by-product characterization previously presented in Table 15 .

Another noticeable difference in the by-product mineralogy is the presence of magnesium-containing minerals in the $\mathrm{PFBC}$ residue. The presence of dolomite and periclase in this by-product is a direct result of the use of dolomite as the sorbent in the CCT process, instead of lime or limestone. The identification of dolomite indicates that there is excess 
sorbent present in the by-product, which was to be expected. These results are consistent with the results of the by-product characterization presented in Table 15 , which shows the $\mathrm{PFBC}$ residue as having a significantly larger $\mathrm{MgO}$ content of $12.89 \%$ as compared to the spray dry scrubber and $\mathrm{CFBC}$ residues which contain $0.70 \%$ and $1.26 \% \mathrm{MgO}$ respectively.

Four other crystalline phases were also positively identified: quartz, hematite, corundum, and mullite. These phases are made up of elements from the ash content of the by-products. Again, these phases are consistent with the by-product characterization that was presented in Table 15, which showed that all three by-products contain significant quantities of quartz, with smaller amounts of corundum and hematite. Mullite, identified in the spray dry scrubber residue, is known to be a dominant mineral formed from the combustion of bituminous coal.

Any additional phases could not be identified due to the complexity of the powder diffraction patterns. An extensive computer search failed to match with certainty the remaining peaks with any well-characterized phases in the powder diffraction files. ${ }^{(56)}$ Possible matches were made among expected phases, such as calcite $\left(\mathrm{CaCO}_{3}\right)$, however missing peaks and intensity differences precluded making positive identification.

Surface characterization of these three CCT by-products by SEM reveals very different morphology. Figure 7 shows a SEM photomicrograph of the spray dry scrubber residue. It is apparent that this by-product is highly crystalline, and that there are at least three distinctly different crystal morphologies. The agglomerate of very fine, small particles, approximately $1 \mu \mathrm{m}$ in size, seen here was found to contain calcium, sulfur, silicon, and oxygen. Several spherical particles of unreacted fly ash, ranging from $3-7 \mu \mathrm{m}$ in size, are also 


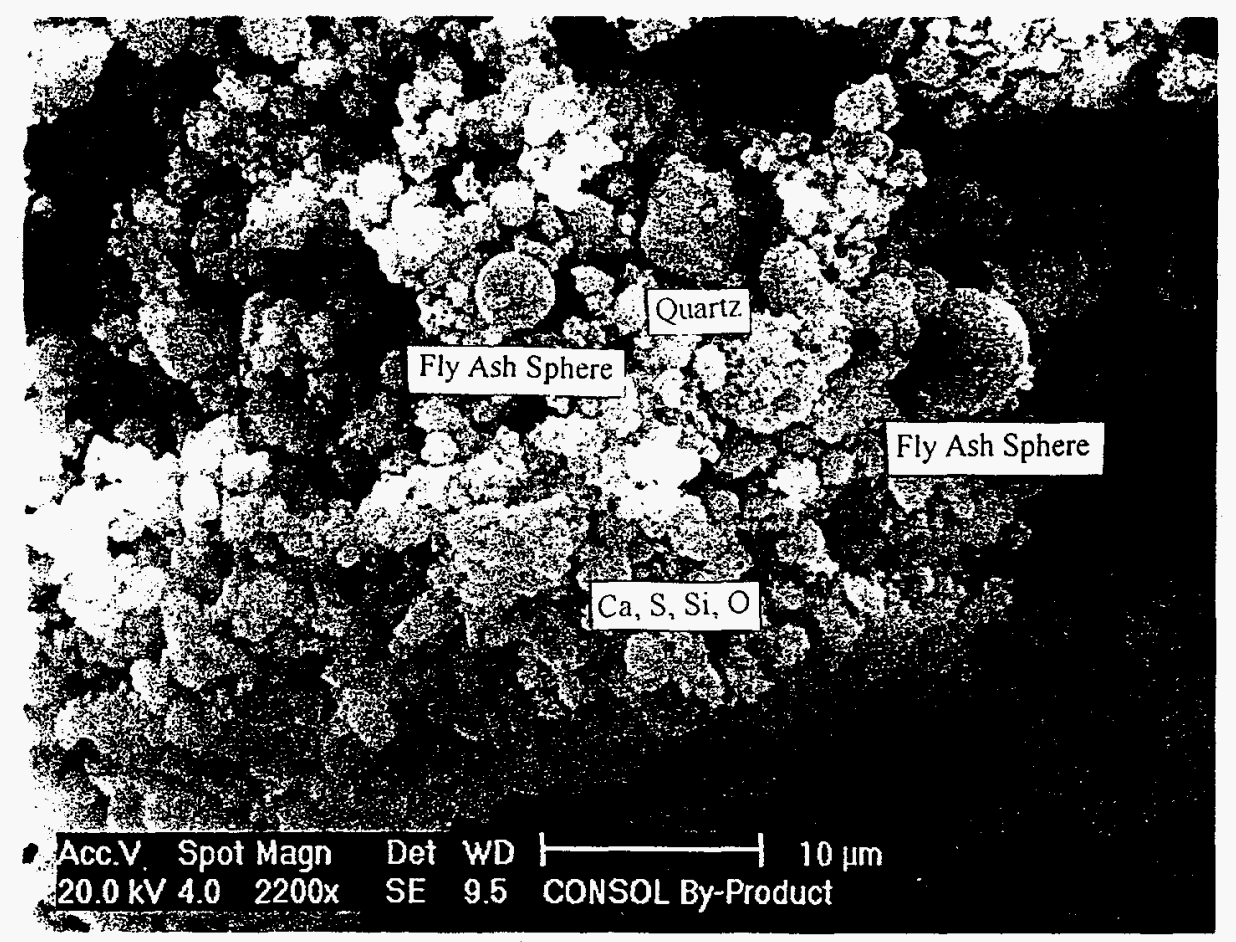

Figure 7 SEM Photomicrograph of the Spray Dry Scrubber Residue

observed in this photomicrograph. These fly ash spheres were found to contain mostly silicon and aluminum, with minor amounts of calcium and iron. The photomicrograph in Figure 7 also shows a particle of quartz, approximately $5 \mu \mathrm{m}$ in size, containing silicon and oxygen. Figures 8 and 9 show SEM photomicrographs of the PFBC and CFBC residues, respectively. The morphology of the $\mathrm{PFBC}$ residue, shown in Figure 8 , is not as easy to differentiate as was the spray dry scrubber residue. In general, however, this material seems to be a dense, sintered mass containing slightly larger particles. There were no fly ash spheres observed in this by-product. The CFBC residue, shown in Figure 9, is comprised of plate-like particles containing silicon and aluminum, with significantly larger particles of quartz. The larger average particle size of this by-product, compared to the spray dry 


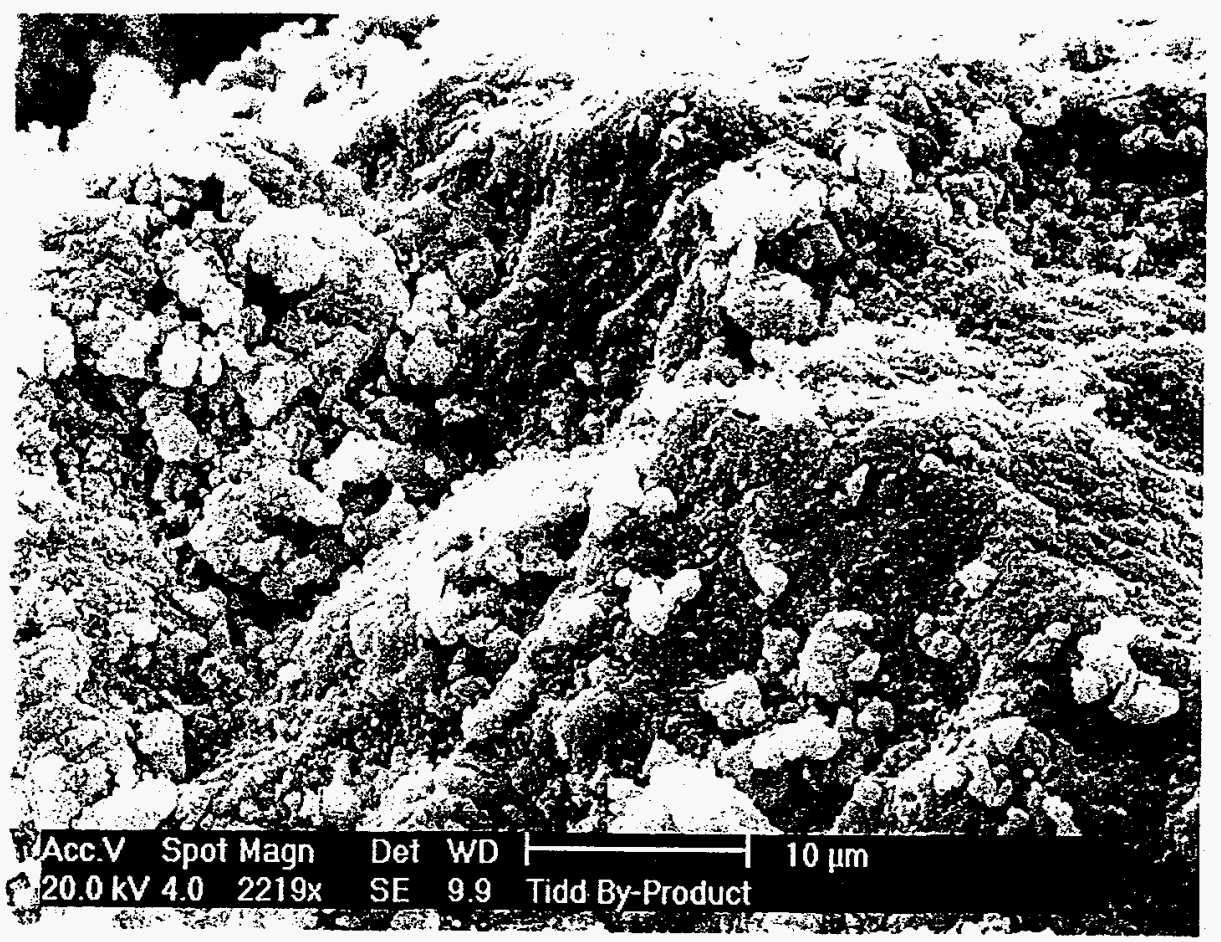

Figure 8 SEM Photomicrograph of the PFBC Residue

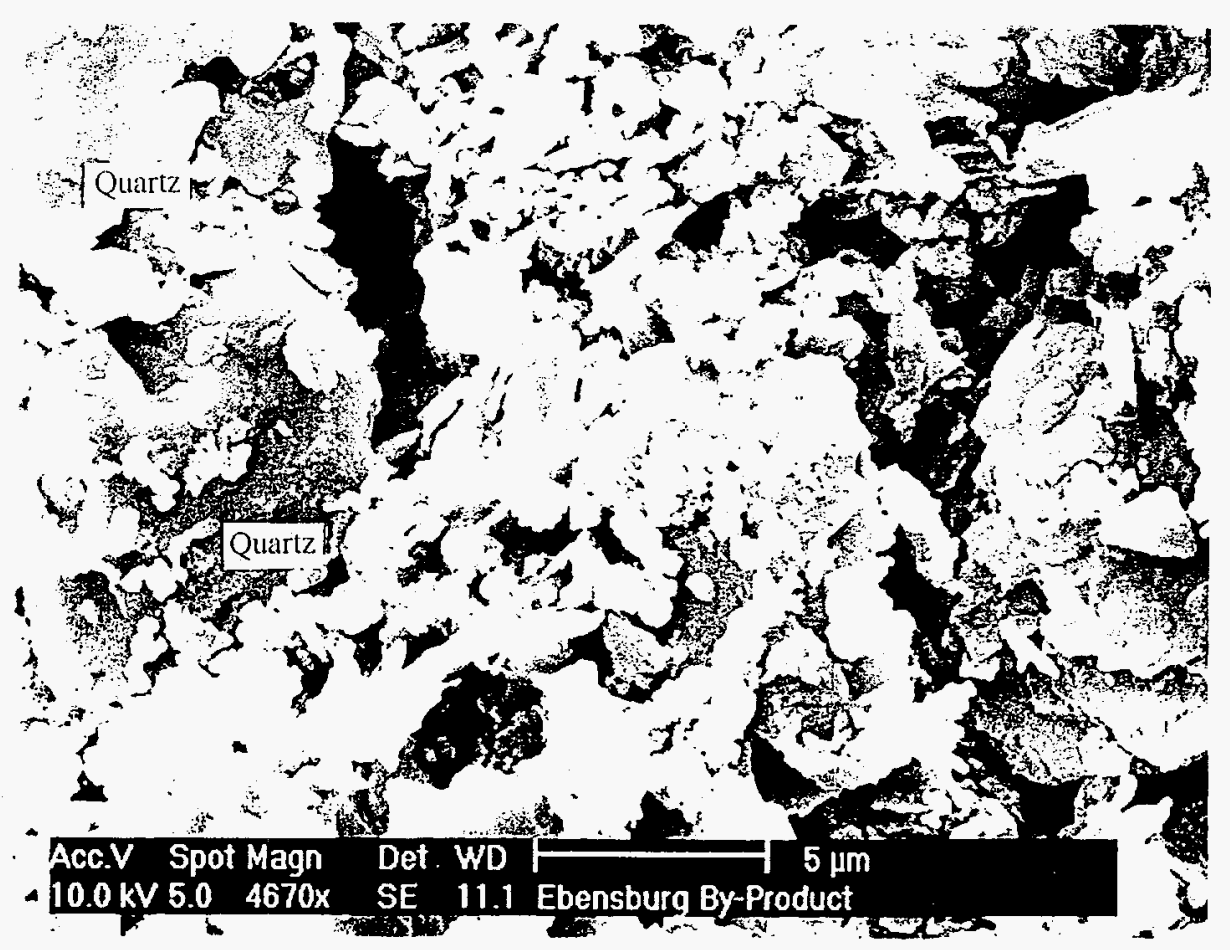

Figure 9 SEM Photomicrograph of the CFBC Residue 
scrubber and $\mathrm{PFBC}$ residues, is in accordance with the physical properties characteristic to these by-products as was presented previously in Table 15. This larger average particle size is primarily due to the bottom ash content of this by-product.

It should be noted that photomicrographs for every by-product sample studied using scanning electron microscopy have not been reproduced in this document to avoid unnecessary repetition. The SEM photomicrographs presented here, however, are characteristically representative of all those obtained during the course of this evaluation and are consistent in composition and morphology with those found during a comprehensive literature review.

The observed smaller particle size of the finer spray dry scrubber residue may be responsible for increased reactivity and decreased porosity. These are desirable characteristics for hazardous waste stabilization. The entrapment of contaminated particles, and thereby the prevention of their release into the environment, is highly dependent upon porosity. Low permeability prevents or retards the release of hazardous constituents into leaching fluids. Low permeability can be associated with either or both low porosity or, more importantly, a pore size distribution fine enough to minimize the transport of leaching fluids containing hazardous constituents. ${ }^{(57)}$ 
standard. For this reason, lead is considered to be a metal of concern. As none of the other fourteen metals in Table 20 have the potential to leach in excess of the corresponding current BDAT standard, lead will be considered the only metal of concern in the subsequent treatability studies.

\subsubsection{Chemistry and Microstructure}

Obviously, it is desirable to know the speciation of the hazardous constituent in the raw waste. For this reason, characterization of the sandblast waste was performed by both SEM and XRD analysis. The results of these analyses are presented and discussed below.

Elemental analysis of the sandblast waste by SEM revealed the presence of four dominant elements: silicon, lead, carbon, and oxygen. A representative SEM spectrum of the sandblast waste is shown in Figure 10. This spectrum shows the dominant presence of lead, which is from the lead-based paint removed during the course of the building rehabilitation project, and silicon from the use silica sand as the abrasive blasting media. Additional minor elements identified in the waste included iron, aluminum, calcium, potassium, and chlorine, however, these were not found in the abundance of the other elements. The iron found in the sandblast waste could conceivably be from the steel reinforcements which support the wooden roof from which the lead-based paint was mechanically removed. As previously mentioned, the unlabeled peak to the left of the calcium peak is palladium, the coating material used to prevent the sample from charging while under the microscope. 


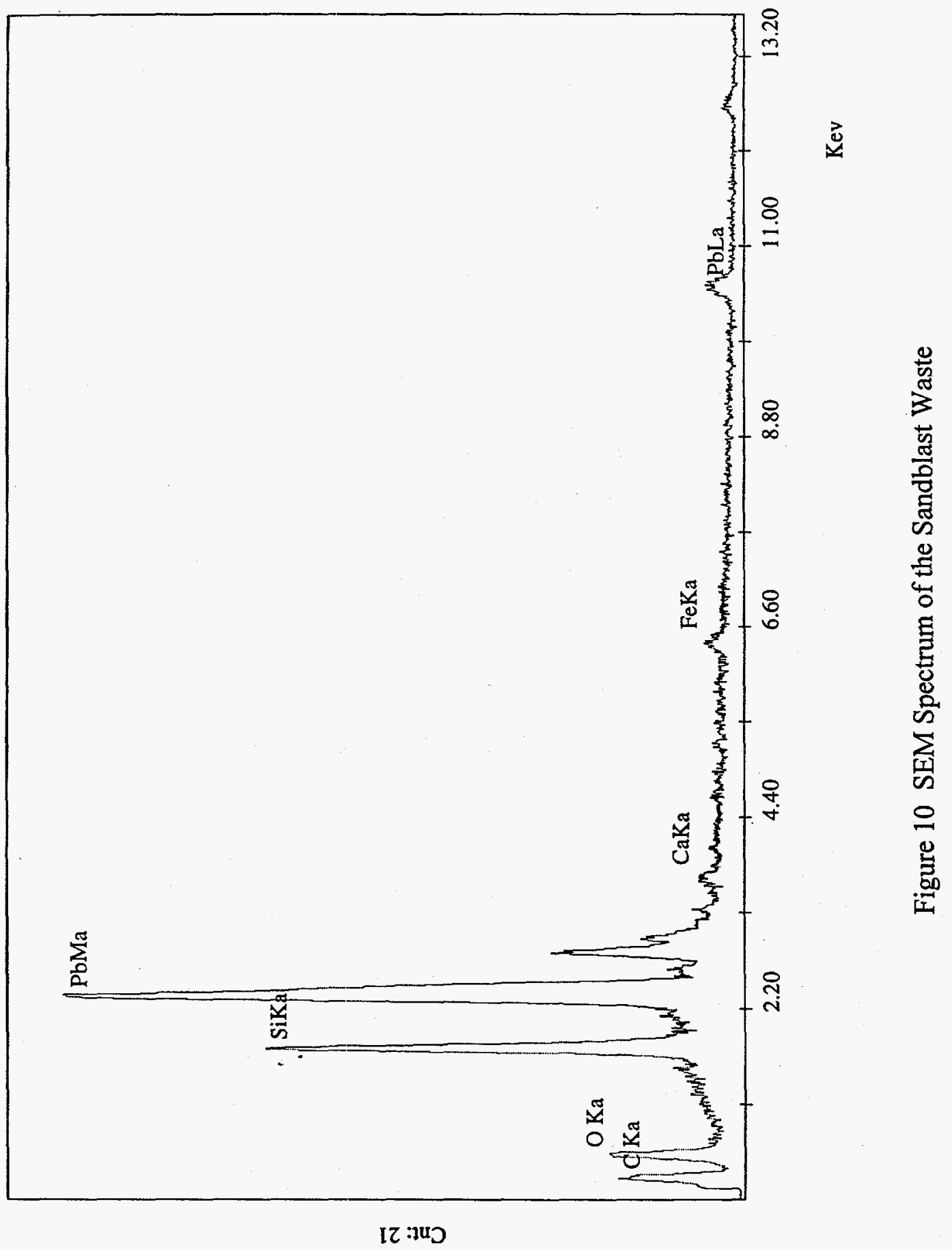


Mineralogical analysis by XRD revealed that quartz $\left(\mathrm{SiO}_{2}\right)$ and hydrocerussite $\left[\mathrm{Pb}_{3}\left(\mathrm{CO}_{3}\right)_{2}(\mathrm{OH})_{2}\right]$ were the corresponding dominant crystalline phases present. The presence of quartz was expected as the abrasive blasting media used in the lead-based paint removal process was silica sand. The discovery of hydrocerussite indicates that the original form of lead in the lead-based paint is a basic lead carbonate. This is a reasonable deduction as the literature review revealed the use of lead carbonate, also known as white lead, as a common additive to paints as a white hiding pigment. Although SEM analysis revealed the presence of five other minor elements in the sandblast waste, no corresponding mineral phases were positively identified using XRD. The results of both the elemental and mineralogical analyses of the sandblast waste are summarized below in Table 21.

Table 21

Elemental and Mineralogical Analyses of the Sandblast Waste

\begin{tabular}{|c|c|c|}
\hline Sample & Elemental Analysis & Mineralogical Analysis \\
\hline $\begin{array}{c}\text { Sandblast } \\
\text { Waste }\end{array}$ & $\mathrm{Si}, \mathrm{Pb}, \mathrm{C}, \mathrm{O}$ (major) & Quartz $\left(\mathrm{SiO}_{2}\right)$ \\
$\mathrm{Al}, \mathrm{Fe}, \mathrm{Ca}, \mathrm{K}, \mathrm{Cl}$ (minor) & Hydrocerussite $\left[\mathrm{Pb}_{3}\left(\mathrm{CO}_{3}\right)_{2}(\mathrm{OH})_{2}\right]$ \\
\hline
\end{tabular}

Surface characterization of the sandblast waste was performed by SEM analysis. Under the microscope, particles of quartz and slivers of wood were observed in the sandblast waste at low magnifications. The quartz present was from the spent blasting abrasives and the wood slivers were from the wooden roof of the building from which the lead-based paint was removed. A representative SEM photomicrograph of the sandblast waste showing silica 
sand particles and wood slivers is given in Figure 11. This photomicrograph was taken in the backscatter electron mode, as compared to the secondary electron mode which reveals topographical contrast based on relief. The backscatter electron mode, which uses a component of contrast due to atomic number difference, was used to locate the lead metal within the waste sample. This technique relies on the basis that electron yield increases with the average atomic number of the region under the beam. As the atomic number of lead is 82 , significantly higher than any of the other elements present in the raw materials, it was possible to locate the lead metal within the waste. The bright areas in the SEM photomicrograph presented in Figure 11 show the location of the lead metal within the waste sample.

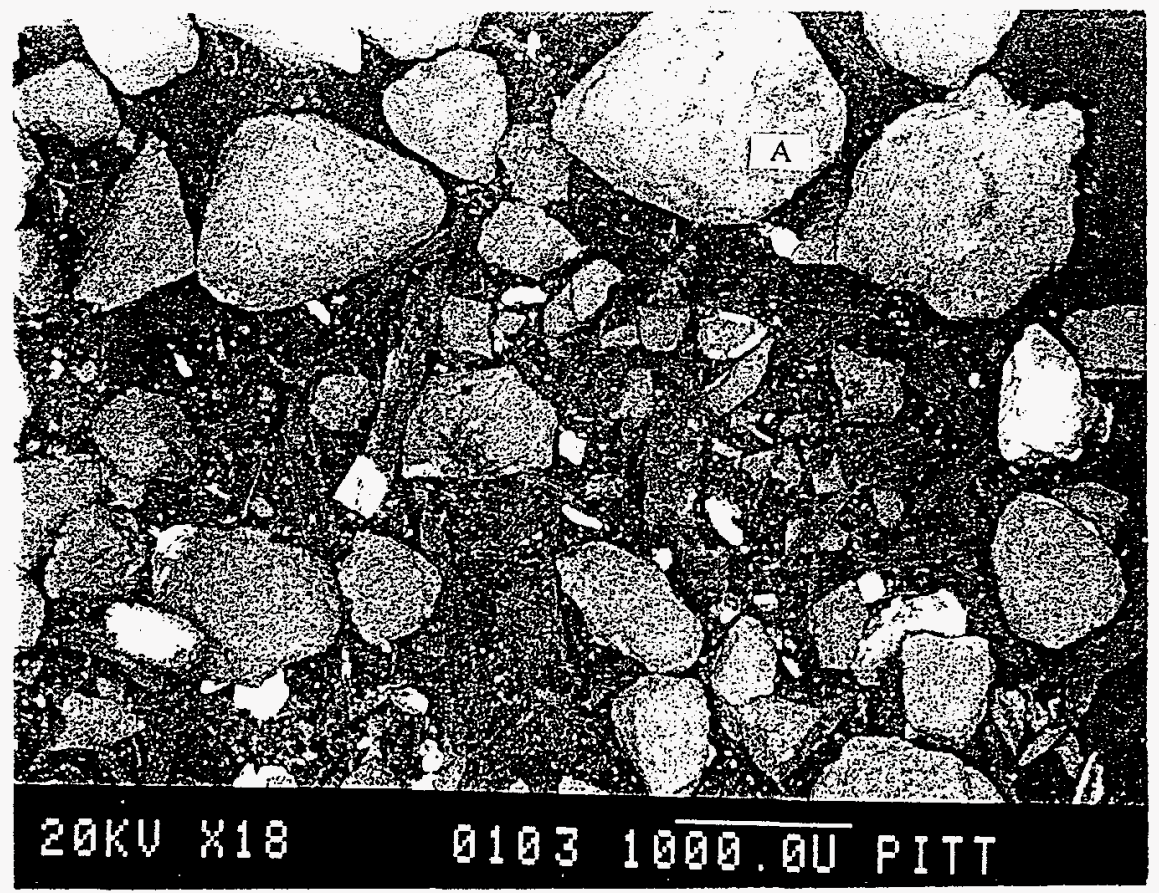

Figure 11 Backscatter Electron SEM Photomicrograph of the Sandblast Waste 
The surface of the grain of silica sand labeled A at the top of Figure 11 has been magnified and is shown below in Figure 12. The magnified image of the surface of this grain of silica sand shows that it has lead carbonate particles and wood slivers embedded in it after impacting the surface from which the lead-based paint was removed. Again, the bright areas in this photomicrograph, or those areas which appear to be white, indicate the location of the lead metal

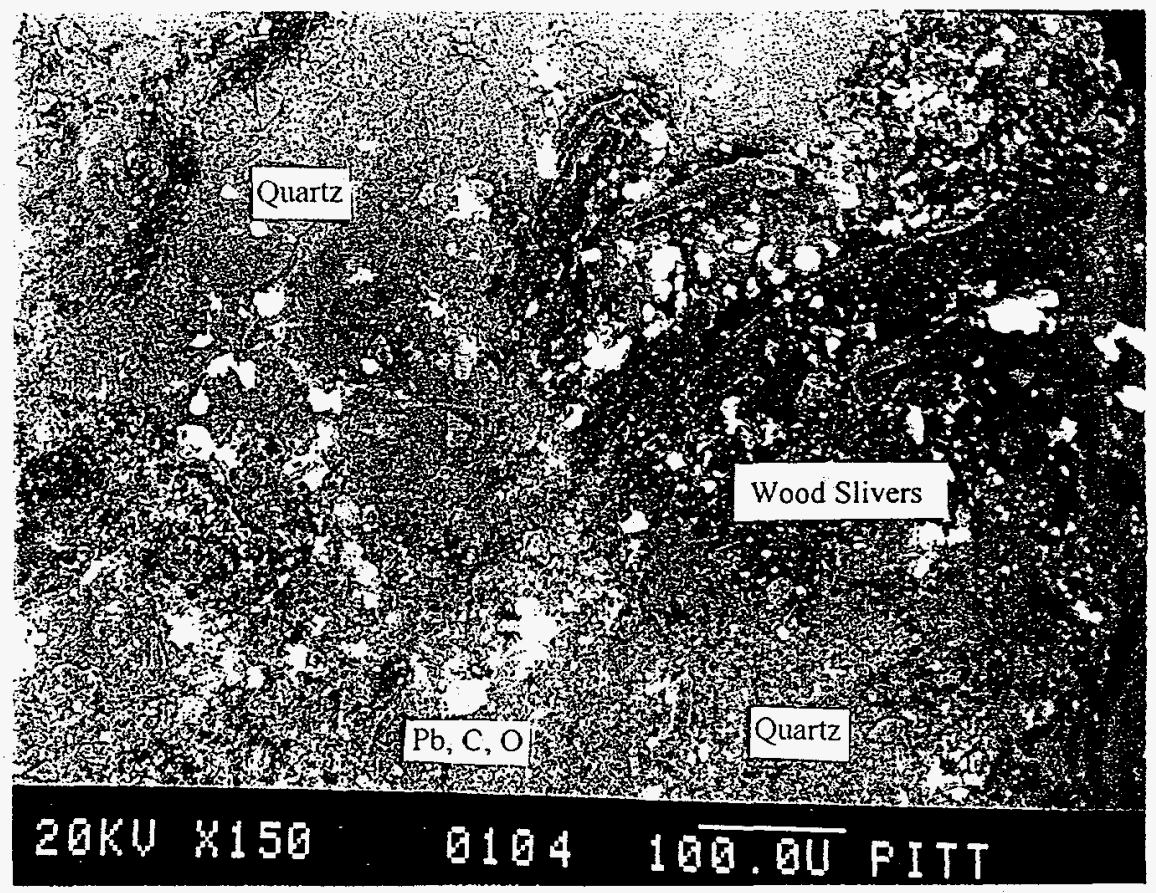

Figure 12 Magnified Image of Wood Slivers and Lead Carbonate Particles Embedded in the Surface of a Grain of Silica Sand 


\subsubsection{Chemistry and Microstructure}

The composition and morphology of the two treated sandblast waste mixtures prepared for solidification testing were evaluated by SEM and XRD techniques. A summary of the resulting elemental analyses and the corresponding mineral phases which could be positively identified is presented below in Table 26.

\section{Table 26}

Elemental and Mineralogical Analyses of the Treated Waste Mixtures

\begin{tabular}{|c|c|c|}
\hline $\begin{array}{c}\text { Sample } \\
\text { Identification }\end{array}$ & Elemental Analysis & Mineralogical Analysis \\
\hline $\begin{array}{l}\text { Sandblast Waste } \\
\text { w/30\% Spray Dry } \\
\text { Scrubber Residue }\end{array}$ & $\begin{array}{c}\mathrm{Ca}, \mathrm{S}, \mathrm{Si} \text { (major) } \\
\mathrm{Al}, \mathrm{Fe}, \mathrm{Mg}, \mathrm{Pb}, \mathrm{C}, \mathrm{O} \\
\mathrm{K}, \mathrm{Ti}, \mathrm{Cl} \text { (minor) }\end{array}$ & $\begin{array}{l}\text { Quartz }\left(\mathrm{SiO}_{2}\right) \\
\text { Calcium Sulfite Hemihydrate } \\
\qquad\left(\mathrm{CaSO}_{3} \cdot 1 \frac{1}{2} \mathrm{H}_{2} \mathrm{O}\right)\end{array}$ \\
\hline $\begin{array}{c}\text { Sandblast Waste } \\
\text { w/50\% PFBC } \\
\text { Residue }\end{array}$ & $\begin{array}{c}\mathrm{Ca}, \mathrm{S}, \mathrm{Si} \text { (major) } \\
\mathrm{Mg}, \mathrm{Pb}, \mathrm{C}, \mathrm{O} \\
\mathrm{Al}, \mathrm{Fe} \\
\mathrm{K}, \mathrm{Ti} \text { (minor) }\end{array}$ & $\begin{array}{l}\text { Quartz }\left(\mathrm{SiO}_{2}\right) \\
\left.\text { Anhydrite }(\mathrm{CaSO})_{4}\right) \\
\text { Dolomite }\left[\mathrm{CaMg}\left(\mathrm{CO}_{3}\right)_{2}\right] \\
\text { Periclase }(\mathrm{MgO}) \\
\text { Hydrocerussite }\left[\mathrm{Pb}_{3}\left(\mathrm{CO}_{3}\right)_{2}(\mathrm{OH})_{2}\right] \\
\text { Hematite }\left(\mathrm{Fe}_{2} \mathrm{O}_{3}\right) \\
\text { Calcium Silicate Hydrate } \\
\qquad\left(\mathrm{Ca}_{2} \mathrm{SiO}_{4}-0.35 \mathrm{H}_{2} \mathrm{O}\right)\end{array}$ \\
\hline
\end{tabular}

Elemental analyses by SEM show that calcium, sulfur, and silicon are the major components present in the sandblast waste treated with $30 \%$ spray dry scrubber residue. 
Additional elements present include aluminum, iron, magnesium, lead, carbon, and oxygen. Minor amounts of potassiun, titanium, and chlorine were also found, but not in the abundance of the other elements. This elemental analysis was found to be consistent with the composition of the raw materials used in the treatment mixture. A representative SEM spectrum of this treated waste mixture, taken after a curing time of 7 days, is presented below in Figure 14. This spectrum shows the dominant presence of calcium, sulfur, and silicon in the treated end-product, in addition to the presence of aluminum and minor amounts iron, potassium, and titanium. It should be noted that spectrums for every treated waste sample analyzed using SEM have not been reproduced in this document to avoid unnecessary repetition, however, representative spectrums have been provided which are characteristic of those generated during the course of this investigation.

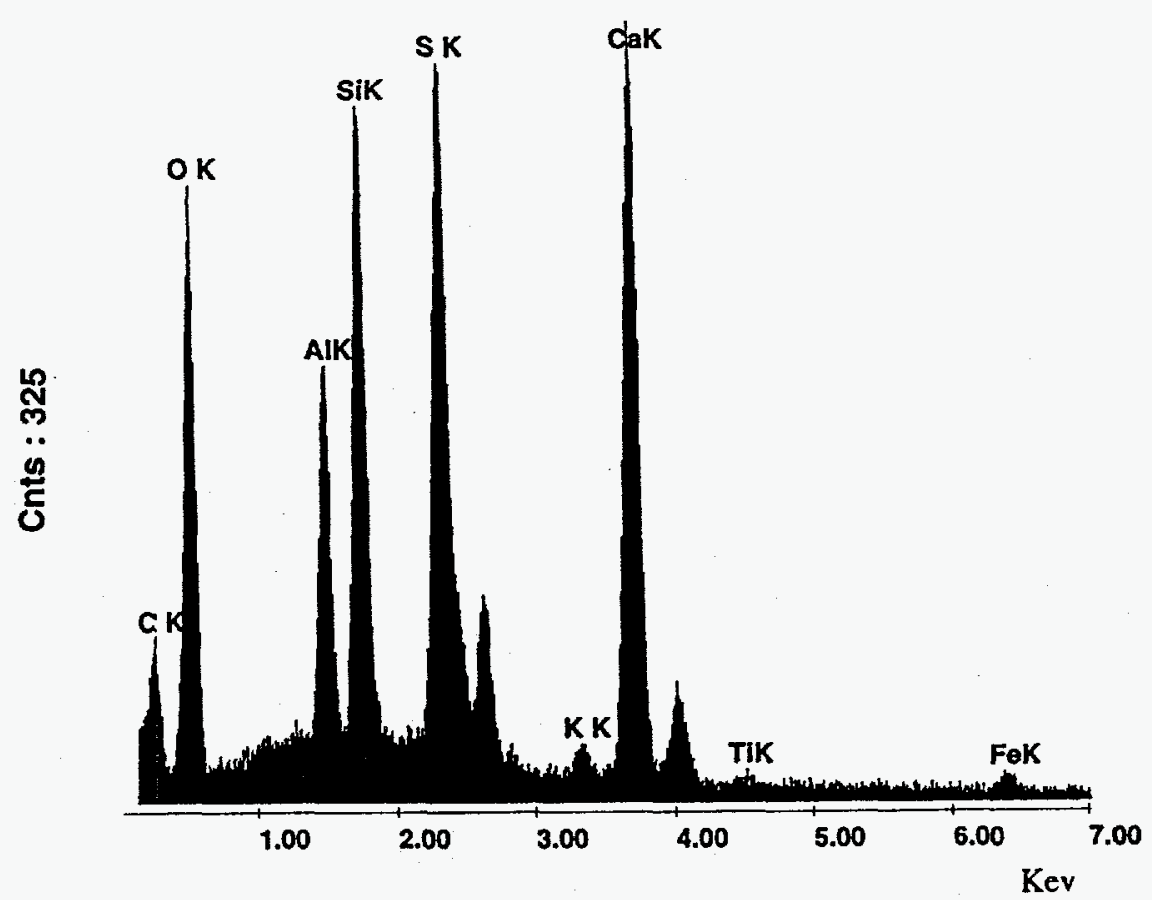

Figure 14 SEM Spectrum of the Sandblast Waste with 30\% Spray Dry Scrubber Residue 
Mineralogical analysis of the sandblast waste treated with $30 \%$ spray dry scrubber residue was performed by XRD. Corresponding mineral phases were positively identified for the major elements present in this treated waste mixture. The dominant crystalline phases were quartz and the sulfur sorption reaction product calcium sulfite hemihydrate. This is consistent with the mineralogy of the raw materials used in the treated waste mixture, as quartz was found to be the dominant element present in the sandblast waste and calcium sulfite hemihydrate was found to be the dominant sulfur sorption reaction product present in the spray dry scrubber residue. No corresponding mineral phases could be positively identified (by matching the position and intensity of the 3 strongest peaks for any given phase in the diffraction patterns) for any of the remaining minor elements present. Although mullite was identified in the spray dry scrubber residue, and aluminum was found in the resulting treated waste mixture, this crystalline phase could not be positively identified in the resulting diffraction patterns. In addition, elemental analysis revealed the presence of lead within the treated waste mixture, however, basic lead carbonate was not positively identified in the resulting XRD patterns. In every case, the quartz particles in the sandblast waste dominated the diffraction patterns. The complex nature of the matrix made identifying any other phases very difficult. It was possible, however, to observe that there were no obvious significant phase changes in the diffraction patterns of this treated waste mixture over the 28-day curing period.

Figure 15 shows a representative diffraction pattern of the sandblast waste treated with $30 \%$ spray dry scrubber residue after curing for a period of 3 days. This $\mathrm{x}$-ray pattern demonstrates the dominant presence of quartz and calcium sulfite hemihydrate in the treated 


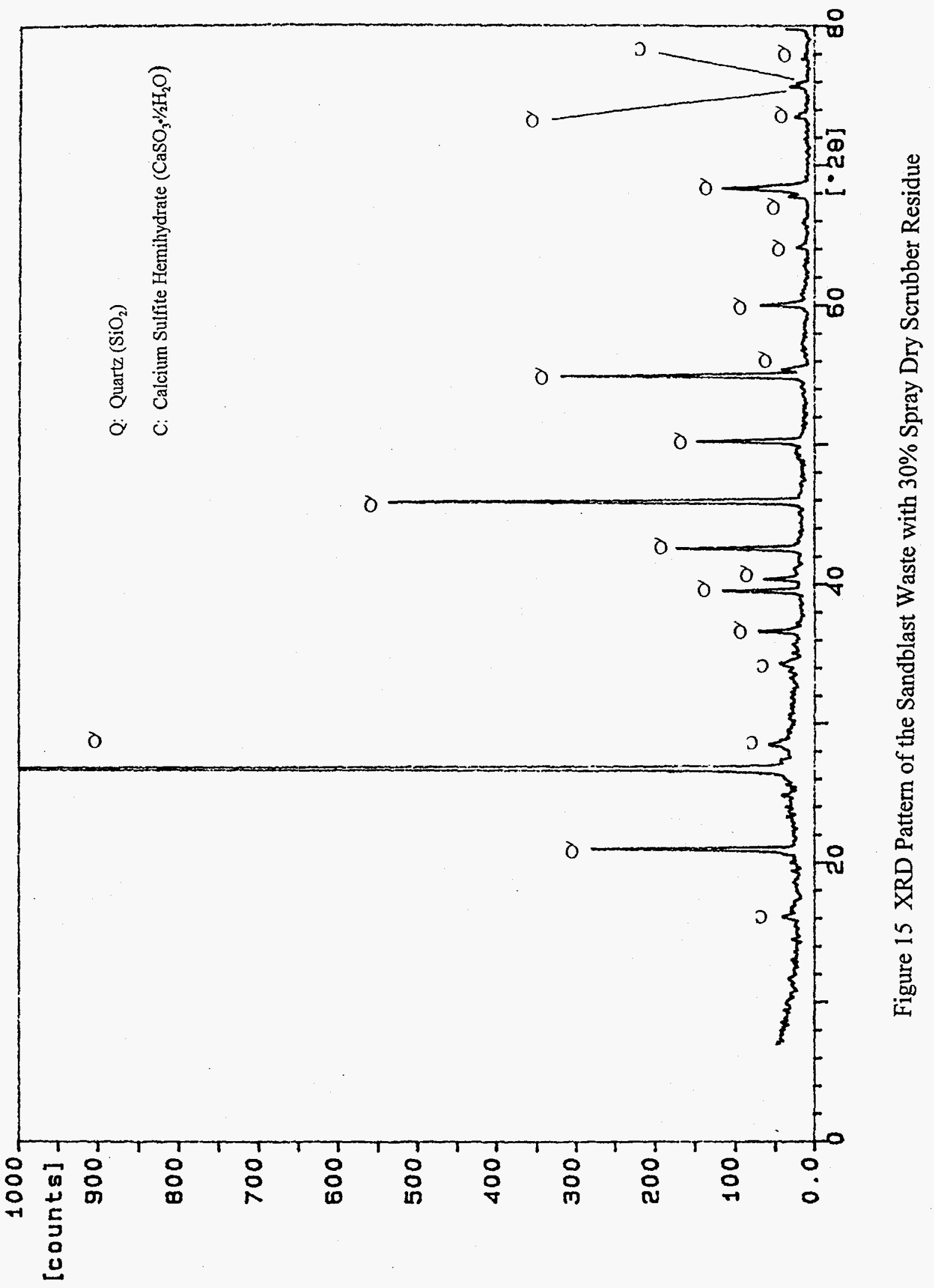


waste mixture. The diffraction pattern given in Figure 15 also shows the presence of many smaller peaks which could not be positively identified.

A greater number of different mineral phases were positively identified in the sandblast waste treated with $50 \%$ PFBC residue, as was shown in Table 22 . Elemental analysis by SEM revealed the presence of several dominant constituents including calcium, sulfur, silicon, magnesium, lead, carbon, and oxygen. Several corresponding crystalline phases were positively identified (again, by matching the position and intensity of the 3 strongest peaks of a given phase with known diffraction patterns) by XRD for each of the major elements present including quartz, anhydrite, dolomite, periclase, hydrocerussite, and calcium silicate hydrate. Alluminum and iron were also found in the treated waste mixture, but not in the abundance of the other elements. Hematite was the mineral phase identified corresponding to the presence of iron in the sample. Finally, trace amounts of both potassium and titanium were also identified during the elemental analyses, however, no corresponding mineral phases were positively identified by XRD. This is not surprising considering the detection limits of XRD are of the order of $1-3 \%$. Overall, these results are consistent with the composition of both the PFBC residue and the sandblast waste. It was expected that a significant phase change would be observed in the diffraction patterns between curing periods of 14 and 28 days, correlating to the time of increase in leachable lead concentration of the treated waste cylinders. No obvious significant phase changes were observed in the diffraction patterns, however, over the 28-day curing period.

A representative XRD pattem of the sandblast waste treated with $50 \%$ PFBC residue, taken after a 3-day curing period, is shown in Figure 16. This $\mathrm{x}$-ray pattern shows the 


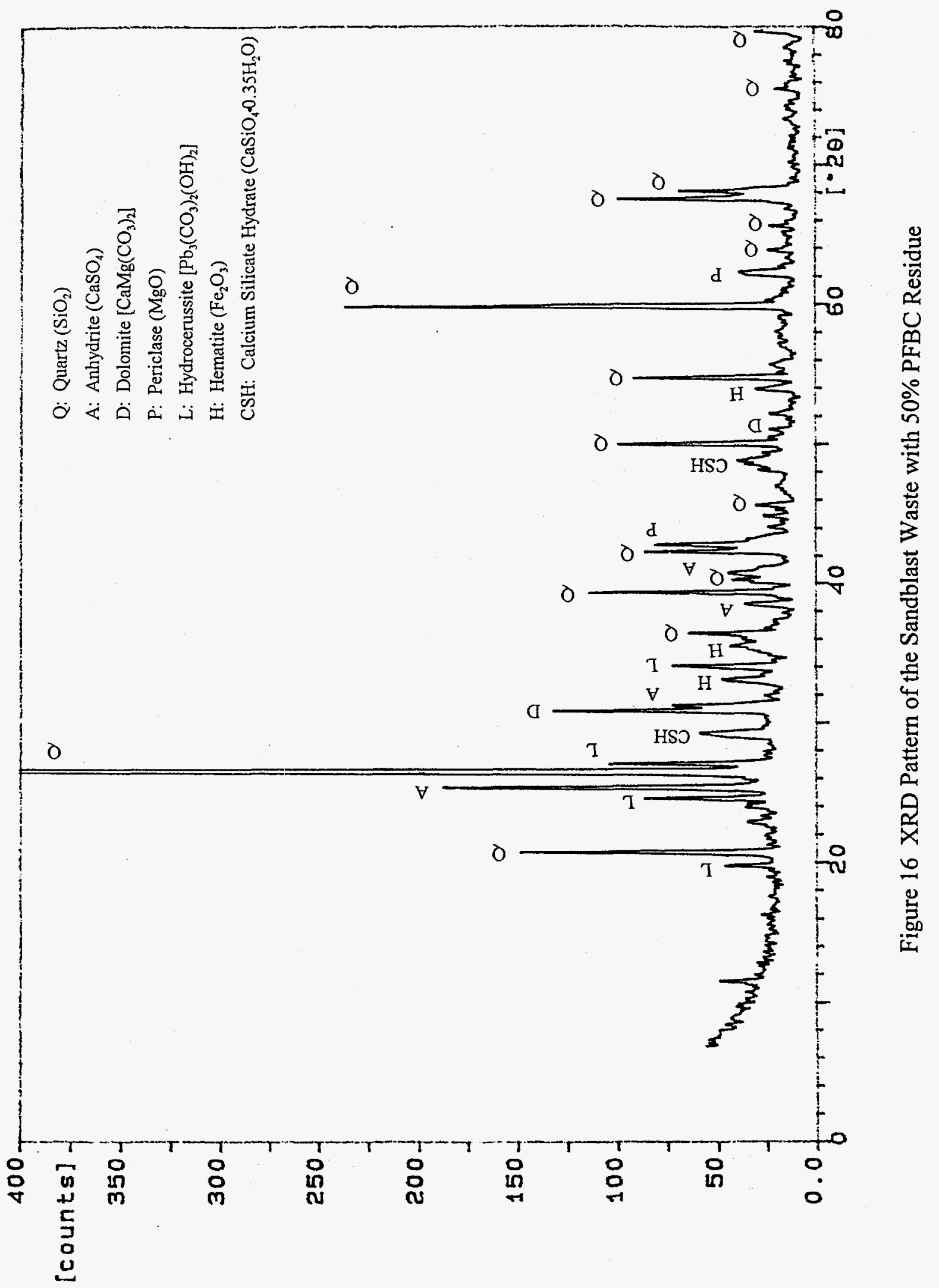


dominant presence of quartz, anhydrite, dolomite, periclase, hydrocenussite, hematite, and calcium silicate hydrate in the treated waste mixture. In addition, it is possible to observe the presence of many unidentified peaks in the diffraction pattern in Figure 16.

The presence of calcium silicate hydrate in the sandblast waste with $50 \%$ PFBC residue, although expected, is a significant discovery. This compound is known for providing strength in cementitious systems. Lime is one of the most important components of these CCT by-products in that it initiates reaction with $\mathrm{SiO}_{2}$ to form calcium silicate. The calcium silicate then reacts with water to form calcium silicate hydrate gel. The free water is chemically bound by this reaction to form hardened calcium silicate hydrate filaments that interlock to provide strength and fill the spaces between particles that were formerly filled by the water. In addition to the development of strength, heavy metal contaminants can be encapsulated in the calcium silicate gel that forms. The benefit of this kind of encapsulation is that the contaminants are physically entrapped and, hence, prevented from leaching. In addition, if the protective structure is degraded, the physical disruption of the particle will only expose the contaminants directly at the surface, providing continued protection of the contaminants in other parts of the particle.

It is this type of encapsulation by a calcium silicate gel that is most likely the dominant mechanism responsible for stabilization in this treatability study. In this manner, the basic lead carbonate (present in both the raw waste and resulting treated wastes mixtures) does not undergo chemical reaction, but rather physical encapsulation. The lead is still in the same form as it was in the raw waste, however, it is protected by the calcium silicate gel coating. Basic lead carbonate is soluble in nitric acid, however, if the leaching fluid is prevented from 
directly contacting the contaminant, the release of lead will be prevented. Even though calcium silicate hydrate was not positively identified by XRD in the sandblast waste treated with $30 \%$ spray dry scrubber residue, and this treatment product did not develop the corresponding compressive strength, elemental analysis by SEM did reveal the presence of calcium and silicon. It is hypothesized that a similar type of calcium silicate gel forms, which encapsulates the lead carbonate particles and prevents the release of lead into the environment. It is difficult to prove this hypothesis by XRD however, as gels are not usually well crystallized and thus do not produce sharp, recognizable $\mathrm{x}$-ray patterns that are easy to identify. If the chemistry of the treated waste is analyzed in conjunction with the microstructure, however, it is possible to infer that the mechanism of stabilization is indeed physical encapsulation.

The morphology of the two treated waste mixtures was qualitatively evaluated by SEM analysis. Figure 17 shows a SEM photomicrograph of the sandblast waste treated with $30 \%$ spray dry scrubber residue after curing for 24 hours. This same image is presented below in Figure 18 using the backscatter electron mode, for which the contrast increases directly with the average atomic number of the phase under the beam, to show the location of the lead metal. The bright spot or white area in the center of this second photomicrograph is an agglomerate of microscopic lead carbonate particles. The very fine material surrounding the lead carbonate particles is comprised of calcium, silicon, and sulfur. The morphology of the encapsulated area is better observed in the photomicrograph presented in Figure 17, which was taken in the secondary electron mode, whereas Figure 18 is presented solely to show the location of the lead within the waste. Another example of the physical entrapment 


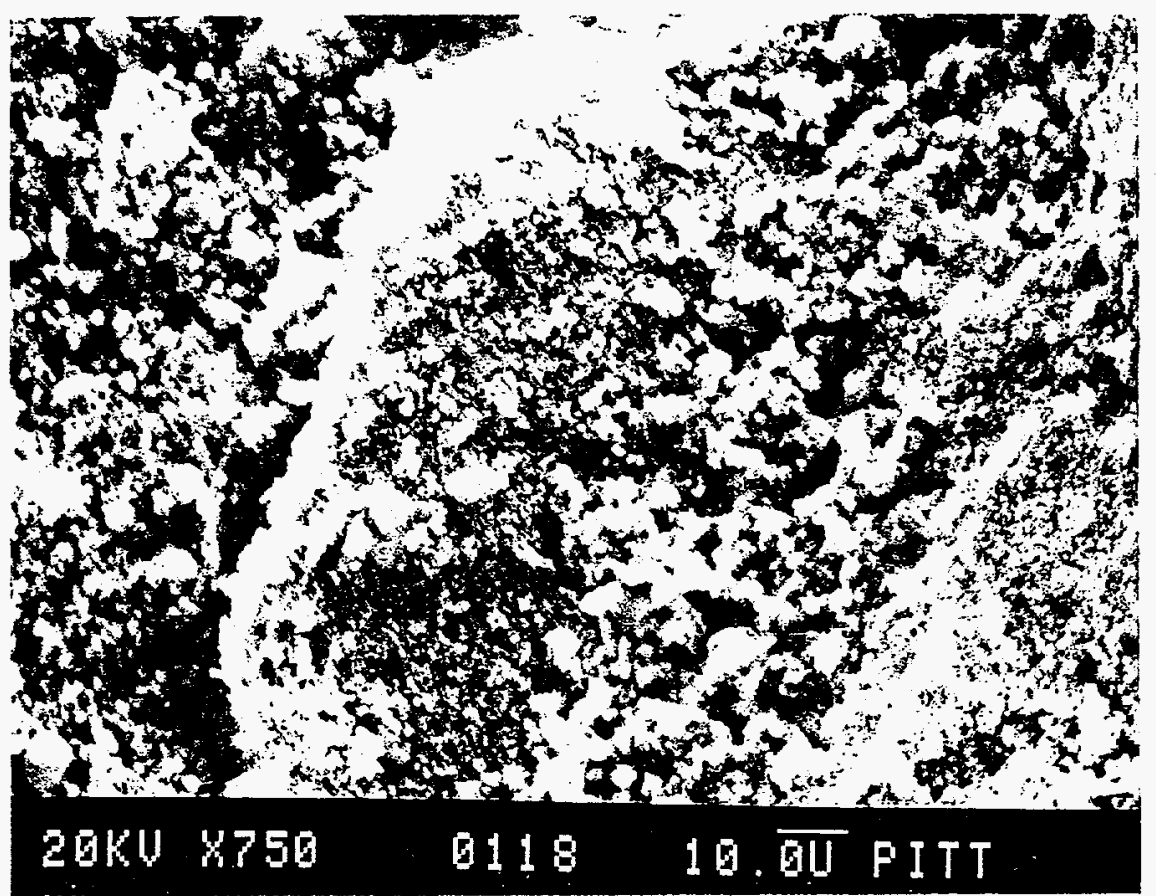

Figure 17 Secondary Electron SEM Photomicrograph of the 1-Day Sandblast Waste Treated with 30\% Spray Dry Scrubber Residue

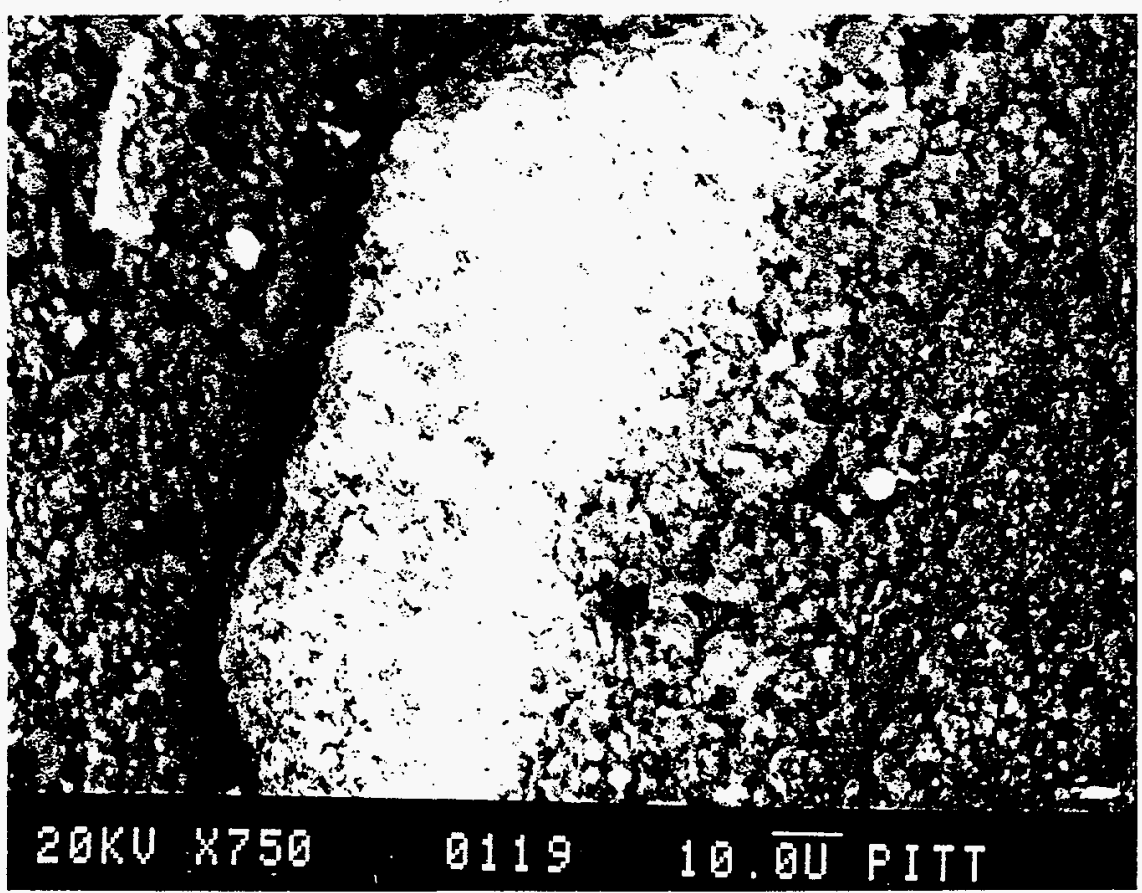

Figure 18 Backscatter Electron SEM Photomicrograph of the 1-Day Sandblast Waste Treated with 30\% Spray Dry Scrubber Residue 
of hazardous constituents at a higher magnification is presented in Figures 19 and 20. These SEM photomicrographs were taken of the sandblast waste with $30 \%$ spray dry scrubber residue after curing for 14 days. While the bright area in the center of Figure 20 shows the presence of lead carbonate, Figure 19 shows that the hazardous constituent is completely surrounded by a matrix of very fine material consisting of calcium, silicon, and sulfur.

The same encapsulation process is demonstrated with the sandblast waste treated with $50 \%$ PFBC residue as shown in Figure 21. This SEM photomicrograph was taken of the treated waste mixture after 28 days of curing. Using the backscatter electron mode, it was possible to show that the agglomerate of microscopic lead carbonate particles in the center of the photomicrograph is physically surrounded by an encapsulating matrix of calcium, silica, and sulfur. In comparison with the previous photomicrographs of the waste treated with the spray dry scrubber residue, there is a noticeable difference in the particle size distribution of the waste treated with the PFBC residue. This larger particle size allows for greater porosity and permeability of the surrounding matrix, thus increasing susceptibility to leaching. This could explain why the sandblast waste treated with the PFBC residue was found to have greater leachable lead concentrations.

As was shown in Figure 13, the leachable lead concentration of the sandblast waste treated with 50\% PFBC residue significantly increased after 28 days of curing. It was hoped that a significant phase change would be observed corresponding to this increased leachable lead concentration, however, comparison of the x-ray patterns for all five curing times failed to reveal any significant phase changes that could be unambiguously identified over this time period. The first appearance of crystal growth in this treated waste mixture, however, was 


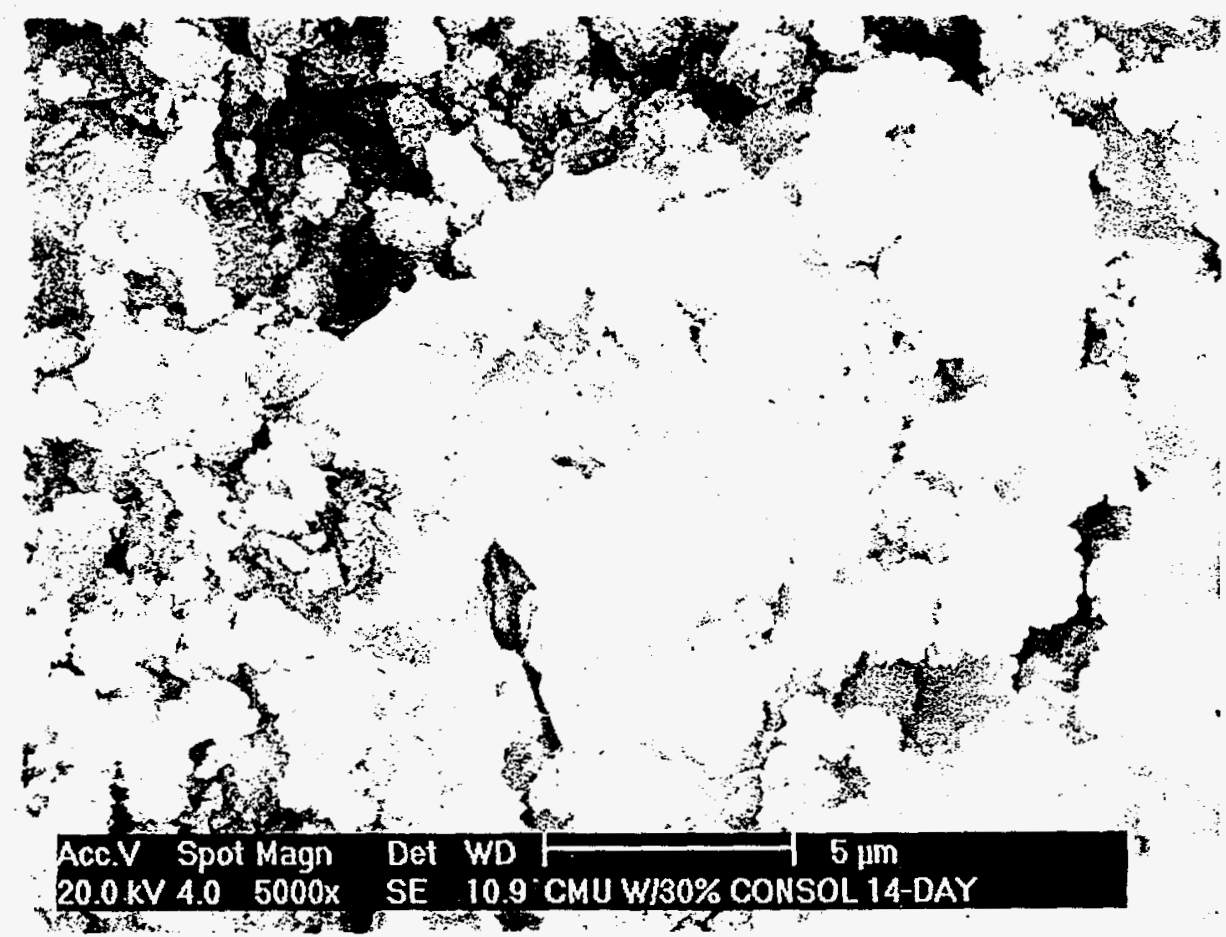

Figure 19 Secondary Electron SEM Photomicrograph of the 14-Day Sandblast Waste Treated with 30\% Spray Dry Scrubber Residue

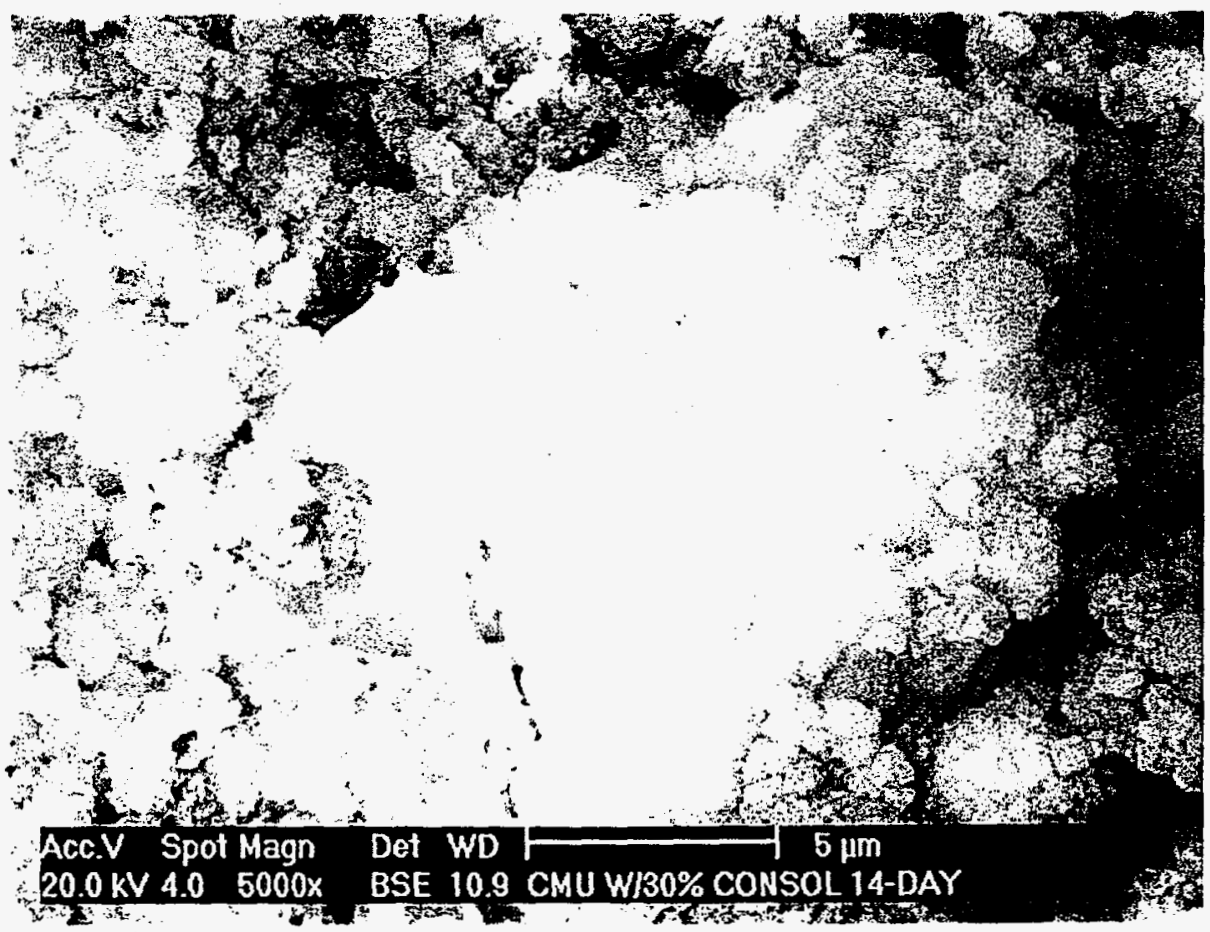

Figure 20 Backscatter Electron SEM Photomicrograph of the 14-Day Sandblast Waste Treated with 30\% Spray Dry Scrubber Residue 


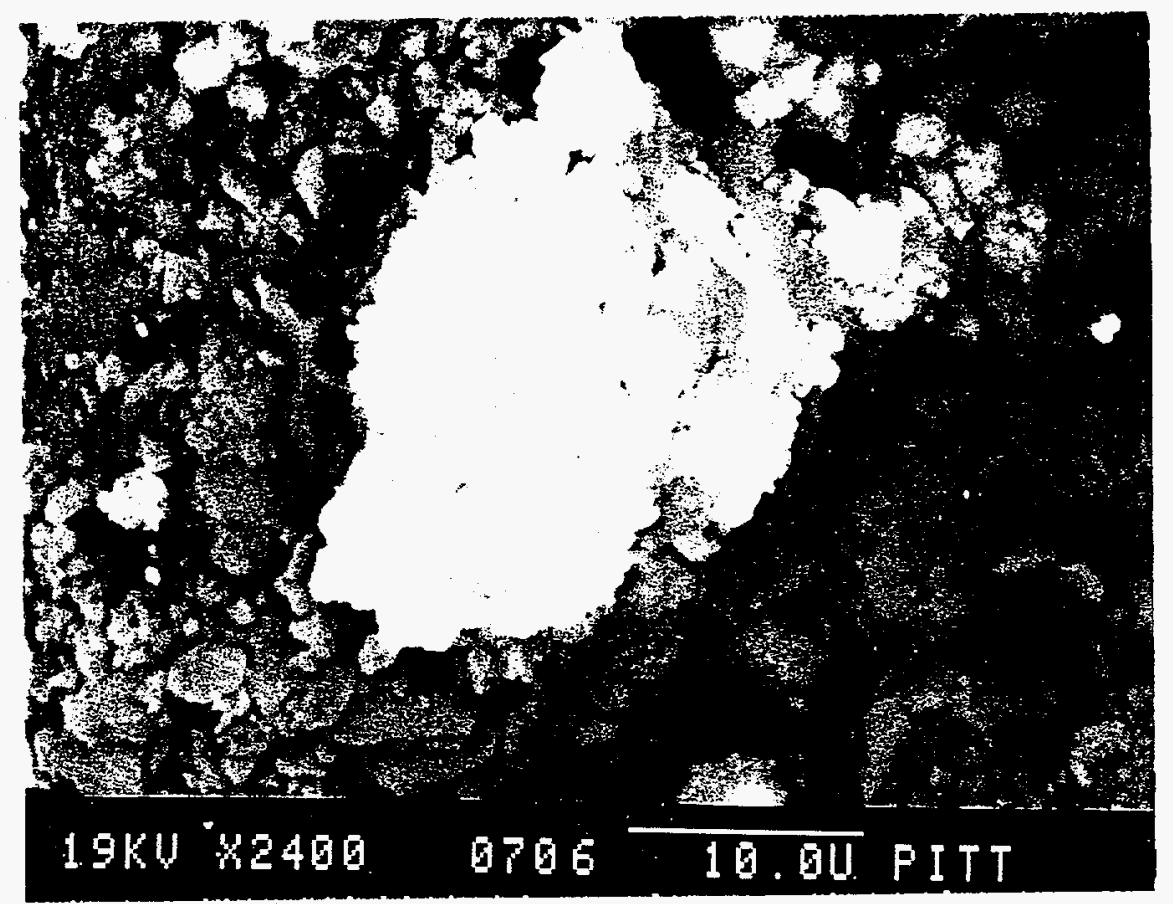

Figure 21 Backscatter Electron SEM Photomicrograph of the 28-Day Sandblast Waste Treated with 50\% PFBC Residue

detected under the microscope at 28 days, directly corresponding to the increase in leachable lead concentration. Figure 22 shows the first appearance of crystal growth at 28 days in the sandblast waste treated with $50 \% \mathrm{PFBC}$ residue. A magnified image of these same crystals is presented in Figure 23

From the literature review, it was expected that ettringite crystals would form in the treated waste mixtures. Although the elemental composition of the crystals observed in Figure 23 could not be positively determined at such high magnification, it is not believed that they are ettringite. The observed crystal formation does not resemble the long, thin, needle-like crystal structures that are characteristic to ettringite formation. In addition, ettringite was not identified in the XRD patterns of any of the treated waste mixtures after 


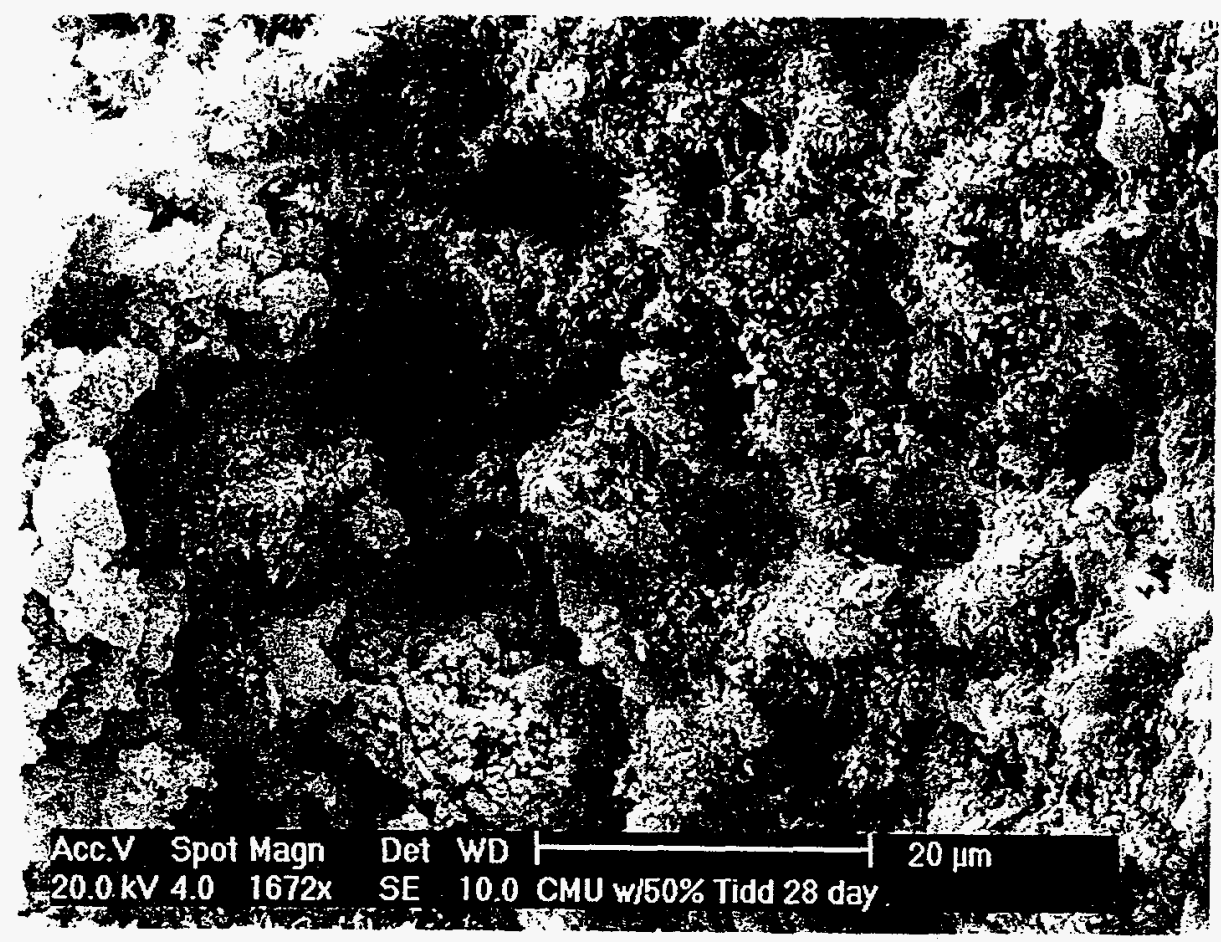

Figure 22 SEM Photomicrograph of the First Appearance of Crystal Growth in the 28-Day Sandblast Waste Treated with 50\% PFBC Residue

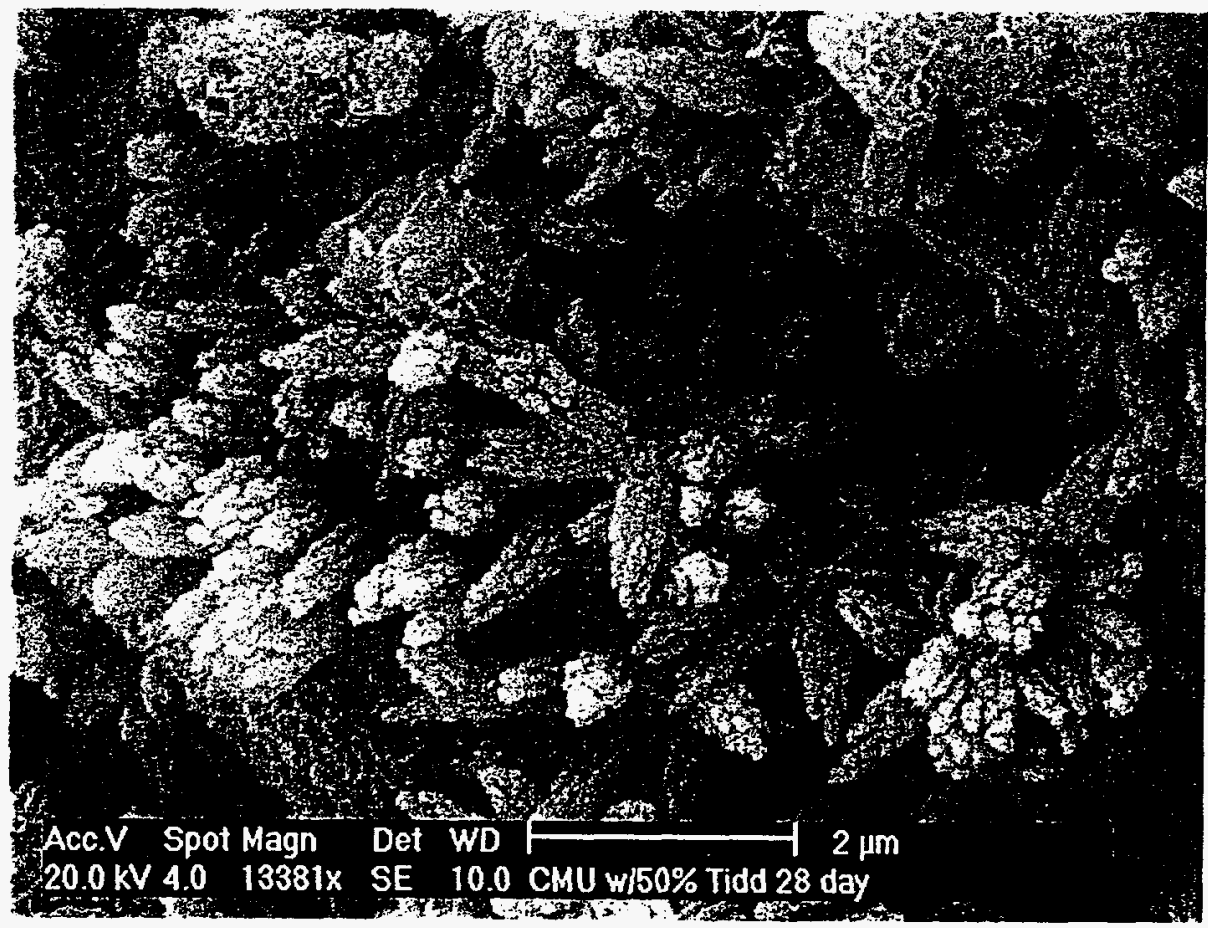

Figure 23 Magnified Image of Crystal Structure of the 28-Day Sandblast Waste Treated with 50\% PFBC Residue 
curing times of $1,3,7,14$, and 28 days. Ettringite is known to form during the first 7 days of curing, however, the first appearance of the crystal growth observed in Figures 22 and 23 did not occur until 28 days. The first appearance of these crystals do, however, correspond with the increased leachable lead concentration of sandblast waste with $50 \% \mathrm{PFBC}$ residue after 28 days. Crystal growth, such as that observed in Figures 22 and 23, and the expansion of sulfur containing compounds could cause the protective encapsulating gel to crack, thus allowing the leaching fluid to gain contact with the contaminants at the fracture surface. This degradation of the encapsulating matrix is most likely responsible for the increased leachable lead concentration observed in the 28-day sandblast waste treated with $50 \%$ PFBC residue.

In summary, agglomerates of microscopic lead particles could be located using the backscatter electron mode and, in every case, these agglomerates were surrounded by a matrix of fine material consisting of calcium, silicon, and sulfur. XRD patterns revealed that lead was present in the treated waste mixtures in its original form in the raw waste, as basic lead carbonate. In addition, XRD analysis of the sandblast waste treated with $50 \%$ PFBC residue revealed the presence of calcium silicate hydrate. These results imply that a calcium silicate gel matrix is formed. This matrix has the potential to bind the hazardous constituent in a stable crystalline lattice by microencapsulation. This system could then close the pore structure of the resulting treated waste product and reduce permeability, thereby preventing leaching fluid from coming in direct contact with the basic lead carbonate particles. The net result would be the microencapsulation of the waste in a gel having low porosity. Thus it can be inferred that the fixation mechanism responsible for successful stabilization is not a chemical process, but rather physical encapsulation as was demonstrated in Figures 17-21. 